\title{
Lexis
}

Journal in English Lexicology

15 | 2020

The adjective category in English

\section{Differentiating synonyms and adjective subclasses by syntactic profiling}

\section{Daniel Henkel}

\section{(2) OpenEdition}

1 Journals

\section{Electronic version}

URL: http://journals.openedition.org/lexis/4428

DOI: $10.4000 /$ lexis.4428

ISSN: 1951-6215

\section{Publisher}

Université Jean Moulin - Lyon 3

\section{Electronic reference}

Daniel Henkel, « Differentiating synonyms and adjective subclasses by syntactic profiling », Lexis [Online], 15 | 2020, Online since 13 June 2020, connection on 18 December 2020. URL : http:// journals.openedition.org/lexis/4428; DOI : https://doi.org/10.4000/lexis.4428

This text was automatically generated on 18 December 2020 .

\section{(c) (i) (9)}

Lexis is licensed under a Creative Commons Attribution-NonCommercial-NoDerivatives 4.0 International License. 


\section{Differentiating synonyms and adjective subclasses by syntactic profiling}

\section{Daniel Henkel}

\section{Introduction ${ }^{1}$}

1 Adjectives are known to have two primary syntactic functions: adnominal (commonly referred to as 'attributive' in English) and predicative, a syntactic property which can even be seen as a defining characteristic of the category across languages (cf. Dixon [2004], Baker [2004], Henkel [2014]).

2 There is tendency, among grammars of English, to describe certain adjectives as 'attributive only', (e.g. mere, utter) or 'predicative only' (e.g. afraid, alive). Huddleston and Pullum's Cambridge Grammar of the English Language [2005: 553] is typical in this regard:

Adjectives that do not normally occur except as (heads of) attributive modifiers include:

\begin{tabular}{|l|l|l|l|l|l|l|}
\hline [1] & damn & drunken & ersatz & erstwhile & eventual & former \\
\hline & frigging & future & latter & lone & maiden & main \\
\hline & marine & mere & mock & only & own & premier \\
\hline & principal & putative & self-confessed & self-same & self-styled & soi-disant \\
\hline & sole & umpteenth & utter & veritable & very & would-be \\
\hline
\end{tabular}

$[\ldots]$ 
One group of very clearly non-attributive adjectives comprises those formed with the prefix $a$ - that originates in the Middle English preposition an "in, on". We list them (excluding some like abed and afire that are rather archaic) in [17]:

\begin{tabular}{|l|l|l|l|l|l|l|}
\hline [17] & ablaze & afloat & afoot & afraid & aghast & agleam \\
\hline & aglimmer & aglitter & aglow & agog & ajar & akin \\
\hline & alight & alike & alive & alone & amiss & askew \\
\hline & asleep & averse & awake & aware & awash & awry \\
\hline
\end{tabular}

Phrases like a child who was asleep do not have attributive paraphrases: *an asleep child is strongly ungrammatical. (Huddleston \& Pullum [2005: 559])

In reality, few adjectives are restricted to a single function. Most "attributive only" adjectives had a predicative function in the past, which may even reappear occasionally:

(1) At first the silence of the night was utter. (R.L. Stevenson, in Shorter Oxford English Dictionary)

(2) It was of no great height, and yet unclimbable, for, after a man had gone up a little way, the sides of it were sheer, offering no foothold [...]. (H.R. Haggard, Nada the Lily).

and even the most "clearly non-attributive" adjectives tend to develop an attributive (or adnominal) function over time:

(3) He was looking at her now, the intensely alive blue eyes sympathetic, penetrating, understanding. (D.G. Philips, The Price She Paid)

(4) [...] but picture their consternation, when all at once the royal lady... threw up the skirt of her mantle and revealed a sight from which the aghast Frenchmen retreated precipitately. (H. Melville, Typee)

It can be demonstrated, however, by examining their distribution across a large number of contexts, that almost all adjectives do in fact have a predisposition for one syntactic function or the other, and can thus be classified as:

1. predominantly adnominal (or 'attributive'),

2. predominantly predicative,

3. syntactically ambivalent.

5 Such profiles were calculated using regular expressions to target high-frequency adjectives in adnominal and predicative constructions in a 5-million-word corpus of public domain literature tagged with TreeTagger for POS and lemma. Previous work (Henkel [2014]) has shown that when the predisposition to adnominal or predicative function is combined with other features, such as intensification (more, less, very), certain semantic classes cluster together. For example, adjectives describing color (red, blue) are strongly predisposed to adnominal function, and resistant to intensification, while adjectives denoting size (big, large, small) are similarly predisposed to adnominal function, but much more receptive to intensification. Among adjectives predisposed to predicative function, those denoting attitudes, emotions or other mental states (glad, 
sorry, happy, sad, anxious) are highly susceptible to intensification, while modal adjectives (possible, impossible, necessary) are not.

6 Previous systems of classification have been proposed by Dixon [2005: 84 sqq.] and Frawley [1992]. Dixon [2005] distinguishes DIMENSION (e.g. big, great, short), PHYSICAL PROPERTY (e.g. hard, strong, clean), SPEED (e.g. quick, fast, slow), AGE (e.g. new, old, young), COLOUR (e.g. white, black, red), VALUE (e.g. good, bad, lovely), DIFFICULTY (e.g. easy, difficult), VOLITION (e.g. deliberate, accidental), QUALIFICATION (e.g. definite, possible, usual, likely), HUMAN PROPENSITY (e.g. fond, angry, happy) and SIMILARITY (e.g. like, unlike, similar, different) as distinct classes of adjectives. Frawley's (1992) classes include VALUE (e.g. good, bad), HUMAN PROPENSITY (e.g. jealous, happy), PHYSICAL PROPERTIES (e.g. hard, soft, thick), COLOR, AGE, QUANTITY and POSSESSION. Both classification systems are based on intuitively assessed semantic features and/or judgments of grammaticality in particular constructions such as those with propositional subjects (Dixon [2005: 87]). The adjective classes that emerge from such analyses are intuitively plausible, useful and largely consistent with one another, but to the best of the author's knowledge, this is the first time empirically obtained quantitative data have been used to confirm the validity of such classes in terms of their syntactic distribution.

7 Moreover, although pairs of antonyms such as happy/sad and large/small have certainly received a great deal of attention in previous studies (so much so that it would be nearly impossible to provide a full accounting) most of these have focused either on the conceptual basis underlying the semantic interpretation of the adjectives in question, or their lexical distribution, i.e. the types of nouns which certain adjectives are most likely to modify.

8 Acceptability judgments have often been used to draw connections between selected syntactic constructions and the underlying conceptual foundations of adjectival meanings. Cruse [1976], for example, distinguishes 3 classes of antonyms on the basis of "committedness" in comparative constructions (i.e. whether $X$ is longer/better/hotter than $Y$ implies $X$ is long/good/hot) and "markedness" in how-questions (i.e. whether How long/short/good/bad/hot/cold is it? does or does not apply to the full scale of length, temperature etc.). More recently, Kennedy [2007] has argued that the acceptability of degree modification, including comparative forms as well as degree markers such as less, too, very, perfectly, and slightly in predicate constructions, can be seen as a syntactic corollary distinguishing adjectives which denote qualities on a closed scale from those that denote gradable qualities on an open scale.

9 Murphy \& Andrew [1993], in a series of experiments asking subjects to produce either synonyms or antonyms from randomly selected adjective-noun combinations, found that synonymy and antonymy, rather than lexicalized relationships between words, are relationships between meanings and therefore highly context-dependent, the antonym varying to a large degree according to the noun that an adjective is used to modify. The importance of adjective-noun associations is given considerable attention as well in Muehleisen's [1997] account which, in addition to a semantic analysis based on a survey of learners' dictionaries, presents an inventory of adjective-noun combinations extracted from a corpus of New York Times articles. By examining the lexical distribution or "semantic range", i.e. the number of different nouns that an adjective is used to modify, the author observes a tendency for adjectives to specialize in certain typical meaning types different from their quasi-synonyms, such as actions for big, in 
contrast with large/small, or facial expressions for happy/sad, in contrast with unhappy. If, in practice, adjectives can be characterized by a relatively small number of common, typical interpretations, it can be surmised that even if synonymy and antonymy are not lexicalized, certain typical, relatively stable oppositions will nonetheless tend to overshadow the multitude of unpredictable, ephemeral or fortuitous interpretations that emerged from Murphy \& Andrew's experiments. This idea finds support in a recent analysis by Paradis et al. [2015] using samples of occurrences from the BNC for 21 antonym pairs manually coded for gradability, "constructional usage pattern" (i.e. attributive vs. predicative syntactic function), "meaning type" of head nouns (concrete, eventive, abstract) and adjectival interpretation (metaphorical, metonymic, or "basic"). The authors conclude that, on the whole, "antonymic partners pattern in a similar way" (Paradis et al. [2015: 184]) with respect to these four criteria so that "[c]anonical antonymic partners are maximally similar and minimally different" (Paradis et al. [2015: 188]). They interpret these findings as evidence that canonicity and conventionalization are in fact reflected in usage profiles and that "lexical knowledge both emerges and develops through language use" (Paradis et al. [2015: 188]). Synonymy and antonymy, it would thus seem, are largely conventional and stable relationships, enough so that they are reflected in usage patterns, even if these never totally capture the full spectrum of interpretations and semantic relations possible.

The present study, which focuses on similarities in usage patterns between adjectives related semantically to one another, not only through synonymy and antonymy (such oppositions are hardly relevant to adjectives denoting colors, for example), will corroborate many of these claims independently. It will be demonstrated, first of all, that antonyms can be classified legitimately as members of the same family, not just on intuitive grounds, but on the basis of empirical evidence that they share a similar distributional profile. Secondly, quasi-synonyms like big/large will be shown to exhibit noticeable disparities in their syntactic profiles which may well be correlated with differences in lexical distribution and semantic interpretation.

11 Among the previously mentioned studies, the approach followed herein is most similar to Paradis et al. [2015] but differs nonetheless in several respects. Rather than the potential "gradability" of adjectival meaning (an important criterion for Kennedy [2007] and Cruse [1976] as well), it is the frequency of specific intensifiers that will be taken into account. The fact that an adjectival meaning is potentially gradable offers no clues as to how often this will actually take place. Not only is receptivity to degree modification in terms of frequency rather than acceptability an important distinctive trait, adjectives which are highly receptive to degree modification may furthermore exhibit affinities with, or resistance to, specific types of degree modification (for example the pair glad/sorry, which are highly susceptible to modification by very, but resistant to comparison, unlike the pair happy/sad). The attributive/predicative opposition once again proves fundamental as well. Adnominal (attributive) occurrences, however, will not be analyzed primarily in connection with the nouns they modify, but their affinity with specific determiners, a dimension which has been mostly overlooked previously. It seems plausible that the affinity with a given determiner could be correlated with tendencies to specialize in certain types of adjective-noun modification, such as the predominance of "first-order" (i.e. concrete) meanings observed by Paradis et al. [2015] for most, but not all, adjectives in adnominal (attributive) constructions. Such a connection remains speculative, however, for the time being, as a thorough analysis of noun semantics would have been beyond the 
scope of the present study, and thus warrants further investigation. Likewise, predicative occurrences will be analyzed, not in relation to nouns, but the most common type of grammatical subject found with predicative adjectives, pronouns, and more precisely by taking into account the opposition between deictic subjects $\left(1^{\text {st }}\right.$ - and $2^{\text {nd }}$-person pronouns) and anaphorical subjects ( $3^{\text {rd }}-$ person pronouns and nouns). The usage patterns analyzed in the following sections are thus primarily syntactic, taking into account contextual parameters which have so far received little attention, with emphasis placed on observable syntactic markers and the configurations in which adjectives most commonly occur in discourse rather than acceptability judgments or detailed semantic interpretation of selected examples.

\section{Methods}

\subsection{Corpus}

The corpus used in this study was compiled from public domain literature available via Project Gutenberg, Classicreader.com and Manybooks.com by authors born in the $19^{\text {th }}$ century who died after 1850. After downloading all available works from this period, a total of 50 works by 50 different authors were selected by size, with preference given to the smallest work by any author containing at least 100,000 words so as to obtain as balanced and diversified a corpus as possible in which no author's individual style or subject matter would exert disproportionate influence. The characteristics of the corpus are displayed in Table 1:

Table 1. Corpus characteristics

\begin{tabular}{|l|l|l|l|l|}
\hline Author & Title & Country & Year & Word count \\
\hline Altsheler, J.A. & The Scouts of the Valley & U.S.A. & 1911 & 108369 \\
\hline Atherton, G.F.H. & The Sisters-In-Law & U.S.A. & 1921 & 113756 \\
\hline Barr, R. & The Sword Maker & U.K. & 1910 & 112296 \\
\hline Barrie, J.M. & Tommy and Grizel & U.K. & 1900 & 126082 \\
\hline Beach, R.E. & The Ne'er-Do-Well & U.S.A. & 1911 & 118289 \\
\hline Bronte, E. & Wuthering Heights & U.K. & 1847 & 117418 \\
\hline Chambers, R.W. & Ailsa Paige & U.S.A. & 1910 & 118902 \\
\hline Conan Doyle, A. & The Return of Sherlock Holmes & UK & 1904 & 112988 \\
\hline Connor, R. & The Major & Canada & 1919 & 119373 \\
\hline Conrad, J. & Victory & U.K. & 1915 & 119667 \\
\hline Farnol, J. & Black Bartlemy's Treasure & U.K. & 1920 & 119235 \\
\hline
\end{tabular}




\begin{tabular}{|c|c|c|c|c|}
\hline Forster, E.M. & Howards End & U.K. & 1910 & 110987 \\
\hline Galsworthy, J. & Beyond & U.K. & 1917 & 118802 \\
\hline Gissing, G. & Veranilda & U.K. & 1903 & 115595 \\
\hline Glaspell, S. & The Visioning & U.S.A. & 1911 & 117591 \\
\hline Green, A.K. & The House of the Whispering Pines & U.S.A. & 1910 & 112860 \\
\hline Grey, Z. & The Desert of Wheat & U.S.A. & 1919 & 120258 \\
\hline Haggard, H.R. & Nada the Lily & U.K. & 1892 & 118230 \\
\hline Hardy, T. & The Mayor of Casterbridge & U.K. & 1886 & 117851 \\
\hline Henty, G.A. & With Lee in Virginia & U.S.A. & 1890 & 124579 \\
\hline Howells, W.D. & The Landlord At Lions Head & U.S.A. & 1897 & 117868 \\
\hline Hume, F. & Madame Midas & U.K. & 1888 & 106552 \\
\hline James, H. & The American & U.S.A. & 1877 & 134619 \\
\hline King, B. & The Street Called Straight & Canada & 1911 & 107232 \\
\hline Kipling, R. & Kim & U.K. & 1901 & 107867 \\
\hline Kyne, P.B. & Cappy Ricks Retires & U.S.A. & 1922 & 114207 \\
\hline Lang, A. & The Red Fairy Book & U.K. & 1890 & 124833 \\
\hline Lawrence, D.H. & Aaron's Rod & U.K. & 1922 & 115261 \\
\hline Lincoln, J.C. & Cap'n Warren's Wards & U.S.A. & 1911 & 107935 \\
\hline London, J. & Burning Daylight & U.S.A. & 1910 & 113526 \\
\hline MacGrath, H. & The Puppet Crown & U.S.A. & 1901 & 106629 \\
\hline Marsh, R. & The Beetle & U.K. & 1897 & 116067 \\
\hline Melville, $\mathrm{H}$. & Typee A Romance of the South Sea & U.S.A. & 1846 & 108079 \\
\hline Norris, F. & McTeague & U.S.A. & 1899 & 114587 \\
\hline Norris, K.T. & Martie The Unconquered & U.S.A. & 1917 & 120047 \\
\hline Oppenheim, E.P. & Peter Ruff and the Double Four & U.K. & 1912 & 119200 \\
\hline Parker, G. & The Right of Way & Canada & 1901 & 123143 \\
\hline Phillips, D.G. & The Second Generation & U.S.A. & 1906 & 114444 \\
\hline
\end{tabular}




\begin{tabular}{|l|l|l|l|l|}
\hline Pyle, H. & The Merry Adventures of Robin Hood & U.S.A. & 1883 & 110875 \\
\hline Reade, C. & White Lies & U.K. & 1857 & 120899 \\
\hline Rees, A.J. & The Hand in The Dark & U.K. & 1920 & 107311 \\
\hline Rinehart, M.R. & Dangerous Days & U.S.A. & 1919 & 120478 \\
\hline Roe, E.P. & A Young Girl's Wooing & U.S.A. & 1884 & 116336 \\
\hline Stratton-Porter, G. & A Girl of the Limberlost & U.S.A. & 1909 & 120621 \\
\hline Thoreau, H.D. & Walden & U.S.A. & 1854 & 116779 \\
\hline Twain, M. & A Connecticut Yankee in King Arthur's Court & U.S.A. & 1889 & 120306 \\
\hline White, S.E. & The Blazed Trail & U.S.A. & 1902 & 112352 \\
\hline Wodehouse, P.G. & Mike & U.K. & 1909 & 107829 \\
\hline Wright, H.B. & The Eyes of the World & U.S.A. & 1914 & 117164 \\
\hline Yonge, C.M. & Nuttie's Father & U.K. & 1885 & 118670 \\
\hline & & Median= & Total= \\
\hline
\end{tabular}

13 The results presented in the following pages are thus relevant to and representative of narrative discourse of the mid to late $19^{\text {th }}$ and early $20^{\text {th }}$ centuries. To what extent further generalizations can be made will, as always, require replication of the analyses presented hereafter with corpora representative of other periods and discourse types. All texts were tagged by part of speech (POS) and lemma using TreeTagger and formatted as Token/POS/lemma as shown in the following example:

- At/IN/at twelve/NN/twelve o'clock/RB/o'clock ,/,/, when/WRB/when the/DT/the sun/NN/ sun peeped/VVN/peep over/IN/over the/DT/the earth-bulge/NN/earth-bulge,$/ /$, they/ $\mathrm{PP} /$ they stopped/VVD/stop and/Cc/and built/VVD/build a/DT/a small/JJ/small fire/NN/ fire on/IN/on the/DT/the ice/NN/ice ./SENT/. (J. London, Burning Daylight)

15 The corpus was then analyzed using regular expressions in TextSTAT 2.9c and AntConc 3.5.8 as described in the following section.

\subsection{Quantitative methods}

\subsubsection{Predisposition to adnominal/predicative function, and affinity with most frequent determiners}

Predisposition to adnominal or predicative function was estimated in two different ways, first by regular expression and then by manual inventory:

1) regular expressions 
The following regular expressions were used first of all to inventory all predictable occurrences of each adjective, i.e. those following a canonical noun phrase or copula verb construction:

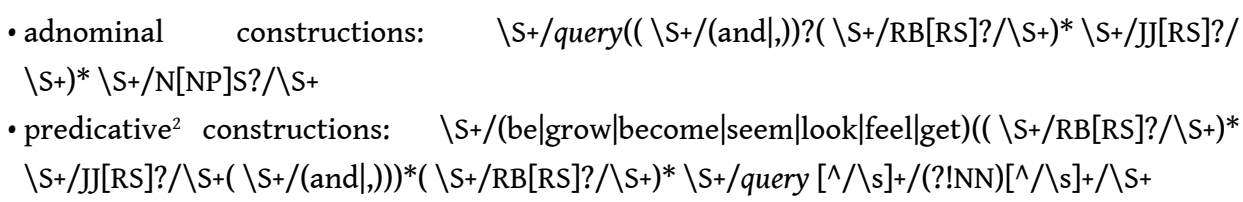

18 2) by manual inventory

Because it is impossible to reliably target configurations in which one of the constituents has no material representation, such as those involving zero determiners, a second inventory was carried out manually. For every adjective included in this study all occurrences (including potentially non-adjectival occurrences) were therefore first of all extracted from the corpus by targeting the lemma with the following regular expression: \S+/query, i.e. any sequence of printable characters ending with a slash followed by the search term, e.g. $\backslash S+/$ old to extract all occurrences of old, as well as older and oldest. These were saved in a spreadsheet, randomized by assigning a number between 1 and 1,000,000 to each occurrence using the RANDBETWEEN function in LibreOffice Calc, after which five random series of 100 occurrences of each adjective were manually verified and annotated according to the determiner for adnominal occurrences, and copula and subject for predicative occurrences. From these random series an average was calculated as well as a $95 \% \mathrm{t}$-distribution ${ }^{3}$ confidence interval for adnominal and predicative function. Likewise, for all adjectives used in noun phrases an average and $95 \%$ confidence interval were calculated for the four most common determiners, i.e. the definite article the, the indefinite article $a(n)$, zero, and possessives my, your, his, etc., which together comprise around $90 \%$ of the syntactic distribution of adnominal adjectives.

19 Adjectives can, of course, be used in other functions than adnominally as modifiers within the noun phrase or in predicative constructions with copula verbs, but given that no other syntactic configuration was found to account for more than $2 \%$ of all occurrences (as explained in the following section) these were only included if adnominal and predicative occurrences were insufficient to account for at least $85 \%$ of the total.

\subsubsection{Receptivity to intensification}

In addition to adjectives themselves, adjective phrases, whether used adnominally or predicatively, may contain adverbial modifiers, most commonly intensifiers such as very, so, too, more/most. Intensification is usually seen as a typical or central characteristic of the category (cf. Huddleston \& Pullum [2002: 528], Quirk \& Greenbaum [1985: 403], inter alia). Predisposition to predicative function and receptivity to intensifiers have been shown to be correlated for the category as a whole (Henkel [2015: 127]) but certain adjectives (most notably sure among those in the present study) are in fact more receptive to intensification in adnominal constructions than when used predicatively.

Receptivity to intensification was evaluated in two different ways:

1) The following regular expressions were used to calculate the percentage of intensifiers in relation to the total number of occurrences, the percentage of adnominal 
constructions containing marks of intensification and the percentage of predicative occurrences containing marks of intensification.

- adjectives used with an intensifier ${ }^{4}$ (very, so, too, more, most, less, least, morphological comparative and superlative) regardless of syntactic function: (( $\backslash \mathrm{S}^{+} /($very|so|too|mo(re|st)| le(ss|ast)) \S+/query)|(\S+/JJ[RS]/query))

- same intensifiers in adnominal constructions: (( \S+/(very|so|too|mo(re|st)|le(ss|ast)) $\backslash \mathrm{S}+/$

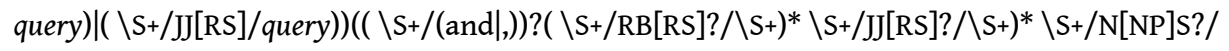
$\backslash \mathrm{S}+$

- intensifiers in predicative constructions: $\backslash S_{+} /$(be|grow|become|seem|look|feel|get)( $\backslash S^{+} /$ $\mathrm{RB}[\mathrm{RS}]$ ? $/ \mathrm{S}+)^{*} \backslash \mathrm{S}+/ \mathrm{JJ}[\mathrm{RS}] ? / \backslash \mathrm{S}+(\backslash \mathrm{S}+/($ and $\left.\mid)),\right)^{*}((\backslash \mathrm{S}+/($ very|so|too|mo(re|st)|le(ss|ast)) $\backslash \mathrm{S}+/$ query $)((\backslash \mathrm{S}+/ \mathrm{JJ}[\mathrm{RS}] /$ query $))[\wedge / \triangle \mathrm{s}]+/(? ! \mathrm{NNS} ?)[\wedge / \mathrm{s}]+/ \wedge \mathrm{S}+$

2) The individual frequency of each mark of intensification was calculated per 100 occurrences of each adjective (or, in other words, as a percentage of the total number of occurrences):

$$
\begin{aligned}
& \backslash \mathrm{S}+/ \mathrm{JJR} / \text { query } \\
& \backslash \mathrm{S}+/ \mathrm{JJS} / \text { query } \\
& \backslash \mathrm{S}+\text { /very } \backslash \mathrm{S}+\text { /query } \\
& \backslash \mathrm{S}+\text { /so \S+/query } \\
& \backslash \mathrm{S}+/ \text { too } \backslash \mathrm{S}+\text { /query } \\
& \backslash \mathrm{S}+\text { /more } \backslash \mathrm{S}+\text { /query } \\
& \backslash \mathrm{S}+\text { /most } \backslash \mathrm{S}+\text { /query } \\
& \backslash \mathrm{S}+/ \text { less } \backslash \mathrm{S}+\text { /query } \\
& \backslash \mathrm{S}+/ \text { least } \backslash \mathrm{S}+\text { /query }
\end{aligned}
$$

24 Taken together, the combination of syntactic function, determiner (for noun phrases), grammatical subject (for predicative constructions) and intensifiers thus provides a comprehensive overview of the most common syntactic configurations in which each adjective can be found.

\section{Results}

\subsection{Adjectives in general}

Before analyzing individual adjectives, a syntactic profile was established for the adjective class as a whole using the regular expression $\backslash \mathrm{S}+/ \mathrm{JJ}[\mathrm{RS}]$ ? $/ \triangle \mathrm{S}+$ to search for all tokens labeled with the POS tags JJ (adjective, e.g. big), JJR (comparative adjective, e.g. bigger) and JJS (superlative adjective, e.g. biggest) as a means of obtaining benchmark data for purposes of comparison.

\subsubsection{Adnominal/predicative predisposition}

A total of 349,530 tokens tagged as adjectives were inventoried in this manner. Of these, approximately $62.3-64.8 \%$ were found in adnominal constructions, with another 15.4-16.8\% in predicative constructions. Together these two syntactic functions account for around $80 \%$ of the syntactic distribution of adjectives in general as shown in Table 2: 
Table 2. ALL ADJECTIVES: Percentage of adnominal and predicative occurrences estimated manually $(M)$ from 5 random samples of 100 occurrences and by regular expressions (R)

\begin{tabular}{|l|l|}
\hline Adnominal & $\begin{array}{l}\text { M: } 64.8( \pm 7.5) \\
\text { R: } 62.3\end{array}$ \\
\hline Predicative & M: $16.8( \pm 5.2)$ \\
R: 15.4
\end{tabular}

The other $20 \%$ of the occurrences were variously made up of:

- object complements:

(5) The pause, the way she was looking at him when he turned back to her, made restraint more and more difficult. (S. Glaspell, The Visioning)

(6) I'm afraid you'll think me captious if I say that nothing could do it.

(B. King, The Street Called Straight)

- "predicative adjuncts" (Huddleston \& Pullum [2002:548]) or "supplementive adjectival clauses" (Quirk \& Greenbaum [1985: 425 sqq.]):

(7) His father was a man of influence and considerable means. He had many friends, good and bad. I do not think the man was intentionally bad, but I do not excuse him. (H.B. Wright, The Eyes of the World)

(8) Had the fiber of our women weakened since then? But he knew it had not. All day, in the new plant, women were working with high-explosives quite calmly. And there were Audrey and the Haverford women, strong enough, in all conscience. (M.R. Rinehart, Dangerous Days)

- exclamations or interjections:

(9) "There was a slight pause, then: "Good! That will do quite as well.

[...]" (R.E. Beach, The Ne'er-Do-Well)

(10) "Honest, it's enough to kill a girl, playing every night and Sunday, and trying to raise children!" she added [...]. (K.T. Norris, Martie The Unconquered)

- nominalizations:

(11) In those days of pestilence, every fever-stricken person was an object of dread to all but the most loving or the most courageous. (G. Gissing, Veranilda)

(12) He is wrong: it is not love only, it is pity: it is remorse for the sorrow I have brought on her, and the wrong I have done poor Raynal. (C. Reade, White Lies)

(13) Was he not disappointed in her for doing that very thing for which he had longed? Was Trina the submissive, the compliant, the attainable just the same, just as delicate and adorable as Trina the inaccessible? (F. Norris, McTeague)

- fixed expressions: 
(14) He still harboured a feeling of resentment against the school in general and Adair in particular, but it was pleasant in Outwood's now that he had got to know some of the members of the house [...]. (P.G. Wodehouse, Mike) (15) For a few moments, Aaron King did not answer. At last, with quiet dignity, he said, "My mother was a remarkable woman, Mr. Lagrange." (H.B. Wright, The Eyes of the World)

(16) Higgins, drawn and haggard beneath his drunken flush, was babbling incessantly; Locke, as usual, sat facing the entrance, his eyes watchful, his countenance alert. (R.E. Beach, The Ne'er-Do-Well)

- as well as dubiously or erroneously labeled tokens, most often involving ambivalent forms with the capacity to function syntactically as either adjectives or adverbs:

(17) "I don't see how I missed it. Wallace, don't you see what those devils will do next?" (S.E. White, The Blazed Trail)

(18) "Oh, look; it's dipping close to the ground, over there in that corner - it's got a nest! We won't go near, will we?" (J. Galworthy, Beyond)

(19) "Nothing less! Your departure from Bleiberg was known to us as early as two o'clock this after-noon," answered the baron. (H. MacGrath, The Puppet Crown) syntactic distribution of the category as a whole, they were not held to be particularly informative or reliable (especially considering the margin of error) as components of the syntactic profile. For certain adjectives, however, most notably those denoting modal concepts and sentiments, it was observed that object complement constructions made up around $10 \%$ of the total number of occurrences, i.e. as much as the proportion of predicative occurrences for most other adjectives. Thus, whenever adnominal and predicative occurrences together made up less than $85 \%$ of the overall distribution of any particular adjective, an attempt was made to identify which other syntactic constructions might help account for the remainder

\subsubsection{Affinities with most frequent determiners}

Most adjectives in English (or at least most adjectives among those commonly used in narrative discourse) are predisposed to adnominal function (cf. Henkel [2014: 381]), but while certain adjectives are used indifferently with any determiner, others may show a strong affinity with one determiner in particular. For example, with old and young around half of all adnominal constructions contain a definite article, whereas for large and small it is the indefinite article that is found in approximately half of all adnominal constructions. Adjectives denoting colors, however, while predisposed to adnominal function as well, are not strongly associated with any specific determiner. In addition to their predisposition to adnominal function, adjectives can thus be further characterized in terms of their affinity for definite determiners, indefinite determiners, or lack of any marked affinity.

Around $90 \%$ of all noun phrases in English, with or without adjectives, contain one of four most frequent determiners: the definite article the, the indefinite article $a(n)$, zero, or possessives my, your, his, etc., while all other determiners combined (some, any, every, this, etc.) represent less than $10 \%$, and at most $1-2 \%$ individually. The proportions ${ }^{5}$ of these determiners in noun phrases containing adjectives are given below in Figure 1:

Lexis, 15 | 2020 
Figure 1. Proportions of co-occurrences of adjectives with determiners (Zero, Indefinite article, Definite article, Possessives, Other determiners) and copula verbs (Pred), expressed as percentages of total occurrences of tokens tagged as adjectives

\section{Syntactic distribution: ALL ADJECTIVES}

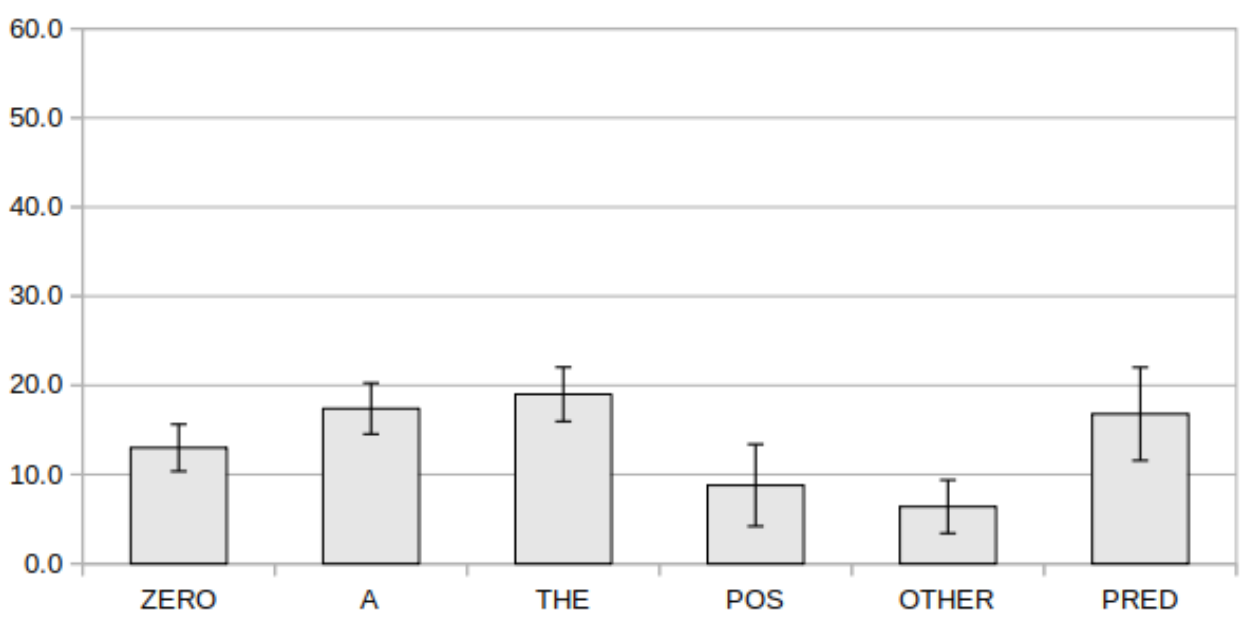

The figures given here are expressed in terms of tokens labeled as adjectives in noun phrases, following copula verbs or in the other various configurations mentioned above (not shown here, but nonetheless included in the calculation of percentages). They do not reflect the proportions of these determiners in noun phrases in general. Previous research (Henkel [2014: 280 sqq.]) suggests that in noun phrases without adjectives definite articles and zero determiners are found in roughly similar proportions, possessives are about 1.5 times more frequent in noun phrases without adjectives ( $16.3 \%$ vs. $9.3 \%$, whereas indefinite articles are over twice as common in noun phrases containing adjectives $(22.5 \%)$ as in those without adjectives $(10.4 \%)^{6}$.

\subsubsection{Receptivity to intensification}

The marks of intensification taken as indicators in the study were found to occur, on average, in about $10 \%$ of adjective phrases regardless of function, with a much higher frequency in predicative constructions than in adnominal constructions (cf. Table 3).

Table 3. Percentage of occurrences containing marks of intensification (all adjectives)

\begin{tabular}{|l|c|}
\hline \% Intensification, all occurrences & 10.2 \\
\hline \% Intensification, adnominal & 5.5 \\
\hline \% Intensification, predicative & 18.9 \\
\hline
\end{tabular}

The most common marks of intensification were found to be the morphological comparative and superlative, to which may be added more and most for adjectives, which do not take the comparative and superlative inflections. The intensifiers very and so make up most of the remainder. 
Table 4. Percentage of individual marks of intensification regardless of syntactic function (all adjectives)

\begin{tabular}{|l|l|}
\hline comparative (JJR) & $2.87(+0.75$ “more" = 3.62) \\
\hline superlative (JJ) & $2.11(+0.59$ “most" = 2.70) \\
\hline very & 1.50 \\
\hline so & 1.59 \\
\hline too & 0.67 \\
\hline more & 0.75 \\
\hline most & 0.59 \\
\hline less & 0.14 \\
\hline least & 0.03 \\
\hline
\end{tabular}

\subsection{Adjectives denoting age: old, young}

34 Adjectives denoting age are strongly predisposed to adnominal function, strongly associated with the definite article the when used adnominally, and highly receptive to intensification when used predicatively.

\subsubsection{Adnominal/predicative predisposition}

Both old and young are strongly predisposed to adnominal function, being used about 10 times more often in noun phrases than in predicative constructions. Together these two functions account for over $90 \%$ of the total distribution of both adjectives.

Table 5. Adjectives denoting age: Adnominal vs. predicative predisposition. Percentage of adnominal and predicative occurrences estimated manually (M) from 5 random samples of 100 occurrences and by regular expressions (R), average for the adjective category

\begin{tabular}{|l|l|l|l|}
\hline & old & young & category \\
\hline \multirow{2}{*}{ \% Adnominal } & $\begin{array}{l}\text { M: } 86.8( \pm 3.2) \\
\text { R } 84.8\end{array}$ & $\begin{array}{l}\text { M: } 89.4( \pm 5.1) \\
\text { R: } 86.5\end{array}$ & $\begin{array}{l}\text { M: } 64.8( \pm 7.5) \\
\text { R: } 62.3\end{array}$ \\
\hline \% Predicative & M: $8.8( \pm 3.8)$ & M: $7.6( \pm 4.2)$ & M: $16.8( \pm 5.2)$ \\
& R: 5.7 & R: 7.0 & R: 15.4 \\
\hline Total & M: 95.6 & M: 97 & M: 81.6 \\
& R: 90.5 & R: 93.4 & R: 77.7 \\
\hline
\end{tabular}




\subsubsection{Affinities with most frequent determiners}

When used adnominally, both old and young exhibit a strong affinity with the definite article, which occurs in roughly half of all the noun phrases containing these two adjectives (i.e. as much as all other determiners combined):

Figure 2. OLD: Percentage of occurrences with most frequent determiners (Zero, Indefinite article "A(N)", Definite article "THE", Possessives, all others). Percentage of occurrences in predicative function

\section{Syntactic distribution OLD}

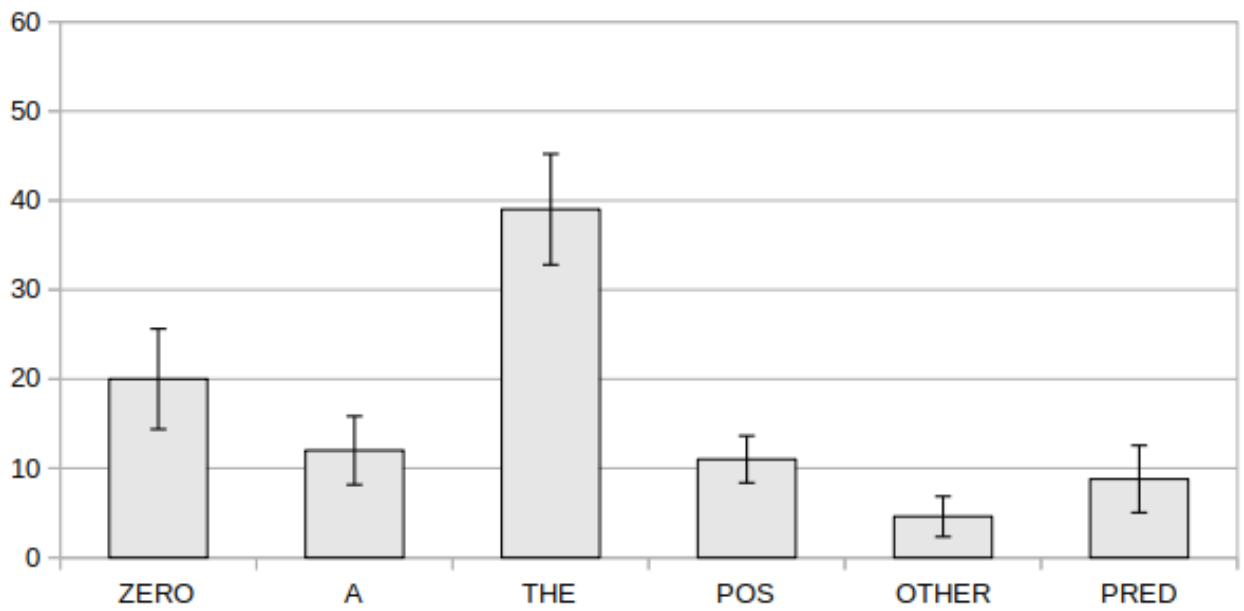

Figure 3. YOUNG: Percentage of occurrences with most frequent determiners (Zero, Indefinite article "A(N)", Definite article "THE", Possessives, all others). Percentage of occurrences in predicative function

\section{Syntactic distribution: YOUNG}

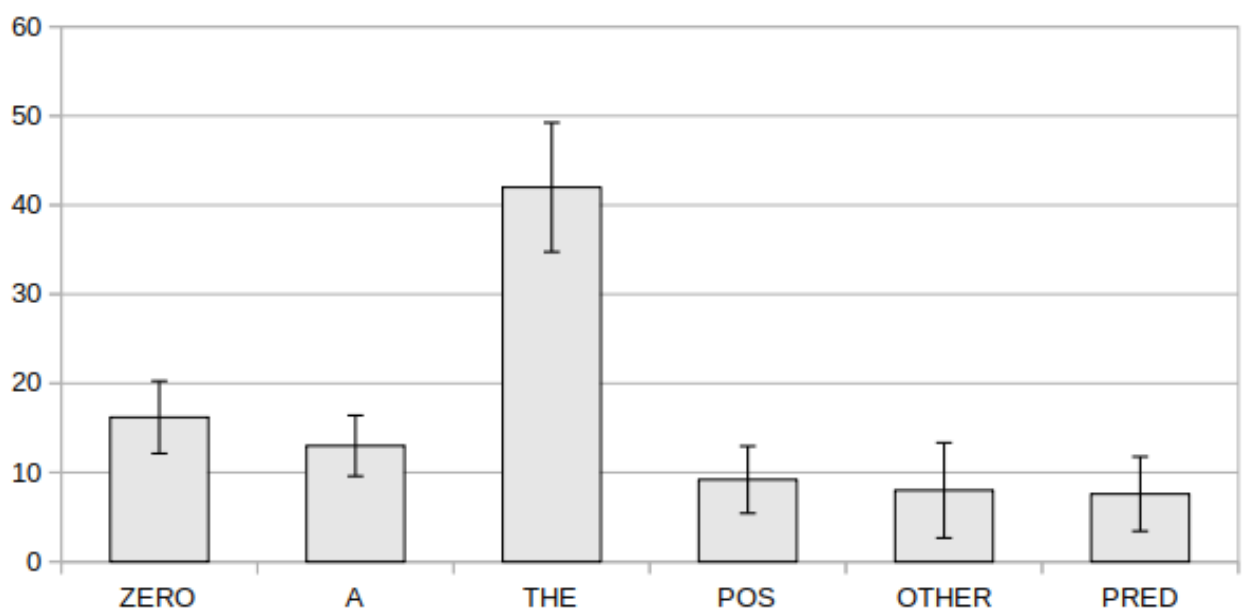

It would be difficult to make any generalizations about the reasons for this affinity with the definite article, as the interpretation of both the adjective and the article are largely dependent on context and the head-noun in particular. Unlike the other adjectives in this study, however, old and young form a small number of high-frequency collocations which thus contribute disproportionately more than any others to the 
overall tendency. The sequences "the old man" ( $\mathrm{n}=430)$, "the old woman" $(\mathrm{n}=187)$ and "the old lady" ( $\mathrm{n}=144)$ together represent $40 \%$ of all occurrences of "the+old $+N$ ", while "the young man" ( $\mathrm{n}=754)$, "the young lady" $(\mathrm{n}=156)$, "the young girl" $(\mathrm{n}=80)$, "the young woman" ( $\mathrm{n}=62)$ and "the young fellow" ( $\mathrm{n}=58+3$ "feller") make up $70 \%$ of all occurrences of "the+young $+N$ ".

While occasional examples with generic reference, like the following, may be found here and there, they remain quite exceptional:

(20) The young man of brains and initiative, of energy, ambition, vision and balance, provided he were honorable as well, and temperate in his pleasures, was the man the eager world was always waiting for. (G.F.H. Atherton, The Sisters-in-Law)

The majority of these occurrences appear to be instances of lexical anaphora:

(21) Daly considered carefully, fixing his flint-blue eyes unswervingly on Thorpe's face. Evidently his scrutiny advised him that the young man (=Thorpe) was a force to be reckoned with. (S.E. White, The Blazed Trail)

(22) Lord Deepmere pursued, directing an eye illumined by this pleasantry toward Mademoiselle Nioche, who was bending gracefully over her lap-dog, apparently absorbed in conversation with it. "I dare say you think it rather odd that I should - a - keep up the acquaintance," the young man (=Lord Deepmore) resumed. "But she couldn't help it, you know, and Bellegarde was only my twentieth cousin. [...]" - And Lord Deepmere's conclusion was lost in the attesting glance which he again directed toward the young lady (=Mlle Nioche). (H. James, The American)

(23) He walked along Collins Street, met a few friends, and kept a look-out for Kitty. He, however, did not see her, but there was a surprise in store for him, for turning round into Swanston Street, he came across Archie McIntosh. Yes, there he was, with his grim, severe Scotch face, with the white frill round it, and Gaston smiled as he saw the old man (=Archie McIntosh), dressed in rigid broadcloth, casting disproving looks on the pretty girls walking along. (F. Hume, Madame Midas)

While the adjective is not strictly necessary to the identification of the referent in such cases:

(21') Evidently his scrutiny advised him that the man was a force to be reckoned with

(22') And Lord Deepmere's conclusion was lost in the attesting glance which he again directed toward the lady

the inclusion of the adjective, depicting the person in greater detail, attenuates the bare categorization that the "determiner+noun" combination alone would assign to the referent. Among the adjectives examined in the present study, such a tendency was only found with adjectives describing age. Whether lexical anaphora attracts these adjectives exclusively, or may be conducive to other forms of modification, and why this should be, would certainly merit further investigation but is beyond the scope of the present article. 


\title{
2.2.3. Receptivity to intensifiers
}

Overall, adjectives denoting age are neither especially receptive nor resistant to intensification, compared with adjectives in general, except in predicative constructions where the frequency of intensifiers is around 2-2.5 times the average for the category. As far as individual markers are concerned, only the comparative occurs with a much greater frequency than for adjectives in general $(5.5 \%$ for old, $6.56 \%$ for young vs. $3.62 \%$ overall).

Table 6. Adjectives denoting age: Intensification and syntactic function. Percentage of occurrences containing marks of intensification ("old", "young" vs. average values for the adjective category) according to syntactic function

\begin{tabular}{|l|l|l|l|}
\hline & old & young & category \\
\hline \% Intensification, all occurrences & 8.5 & 11.4 & 10.2 \\
\hline \% Intensification, adnominal & 3.9 & 6.5 & 5.5 \\
\hline \% Intensification, predicative & 48.9 & 35.8 & 18.9 \\
\hline
\end{tabular}

Table 7. Adjectives denoting age: intensifiers. Percentage of individual marks of intensification regardless of syntactic function ("old", "young" vs. average values for the adjective category)

\begin{tabular}{|l|l|l|l|}
\hline & old & young & category \\
\hline comparative & 5.5 & 6.56 & $2.87(+0.75$ "more" = 3.62) \\
\hline superlative & 1.1 & 1.79 & $2.11(+0.59$ "most" = 2.70) \\
\hline very & 0.6 & 1.28 & 1.50 \\
\hline so & 0.4 & 0.86 & 1.59 \\
\hline too & 0.8 & 0.7 & 0.67 \\
\hline more & 0.03 & 0.06 & 0.75 \\
\hline most & 0.02 & 0.06 & 0.59 \\
\hline less & 0.0 & 0.02 & 0.14 \\
\hline least & 0.0 & 0.02 & 0.03 \\
\hline
\end{tabular}

\begin{abstract}
The receptivity to comparative forms in predicative function can be explained, perhaps, by the fact that age is inherently variable in time and, while objectively measurable in principle, cannot actually be perceived visually but only inferred in an approximate manner, hence the frequency of examples like the following:
\end{abstract}


(24) My game is done; and when she gets older and understands life better, Kathleen will say, 'Poor Charley - he might have been anything!' (G. Parker, The Right of Way)

(25) Madame de Cintre was rather thin, and she looked younger than probably she was. (H. James, The American)

Adjectives denoting age can thus be shown to share a distinctive syntactic profile insofar as both old and young exhibit stronger than average predisposition for adnominal function, a much stronger affinity with the definite article and much higher receptivity to intensification in predicative function, comparative forms in particular.

\subsection{Adjectives denoting size: large, small, big}

Like adjectives denoting age, adjectives denoting size are strongly predisposed to adnominal function, but are strongly associated with the indefinite article, with the exception of big, and are highly receptive to intensification both in adnominal and predicative function.

\subsubsection{Adnominal/predicative predisposition}

Adjectives of size are used adnominally around 6-8 times more often than in predicative constructions (a somewhat more moderate predisposition, compared to adjectives of age, though hardly balanced). These two primary functions make up around $80-90 \%$ of the syntactic distribution of these adjectives. The expression at large accounts for another $3 \%$ of the occurrences of large.

Table 8. Adnominal vs. Predicative predisposition: adjectives of size (large, small, big): Percentage of adnominal and predicative occurrences estimated manually $(M)$ from 5 random samples of 100 occurrences and by regular expressions $(R)$ average for the adjective category

\begin{tabular}{|l|l|l|l|l|}
\hline & large & small & big & category \\
\hline \multirow{2}{*}{ \% Adnominal } & $\begin{array}{l}\text { M: } 76.4( \pm 6.7) \\
\text { R: } 71.8\end{array}$ & $\begin{array}{l}\text { M: } 83.4( \pm 1.4) \\
\text { R: } 79.3\end{array}$ & $\begin{array}{l}\text { M: } 79.0( \pm 3.8) \\
\text { R: } 77.6\end{array}$ & $\begin{array}{l}\text { M: } 64.8( \pm 7.5) \\
\text { R: } 62.3\end{array}$ \\
\hline \multirow{2}{*}{ \% Predicative } & M: $12.4( \pm 4.4)$ & M: $9.8( \pm 0.6)$ & M: $10.6( \pm 4.5)$ & M: $16.8( \pm 5.2)$ \\
& R: 9.0 & R: 6.2 & R: 8.3 & R: 15.4 \\
\hline Total & M: 88.8 & M:93.2 & M: 89.6 & M: 81.6 \\
& R: 80.8 & R: 85.5 & R: 85.9 & R: 77.7 \\
\hline
\end{tabular}

\subsubsection{Affinities with most frequent determiners}

The pair large and small exhibit a strong affinity with the indefinite article, which is used more often with large than all other determiners combined, and more often with small than the combination of the other three most frequent determiners. The profile for big is different in this respect, as both indefinite and definite articles occur in similar proportions (25-30\%). 
Figure 4. LARGE: Percentage of occurrences with most frequent determiners (Zero, Indefinite article "A(N)", Definite article "THE", Possessives, all others). Percentage of occurrences in predicative function

\section{Syntactic distribution: LARGE}

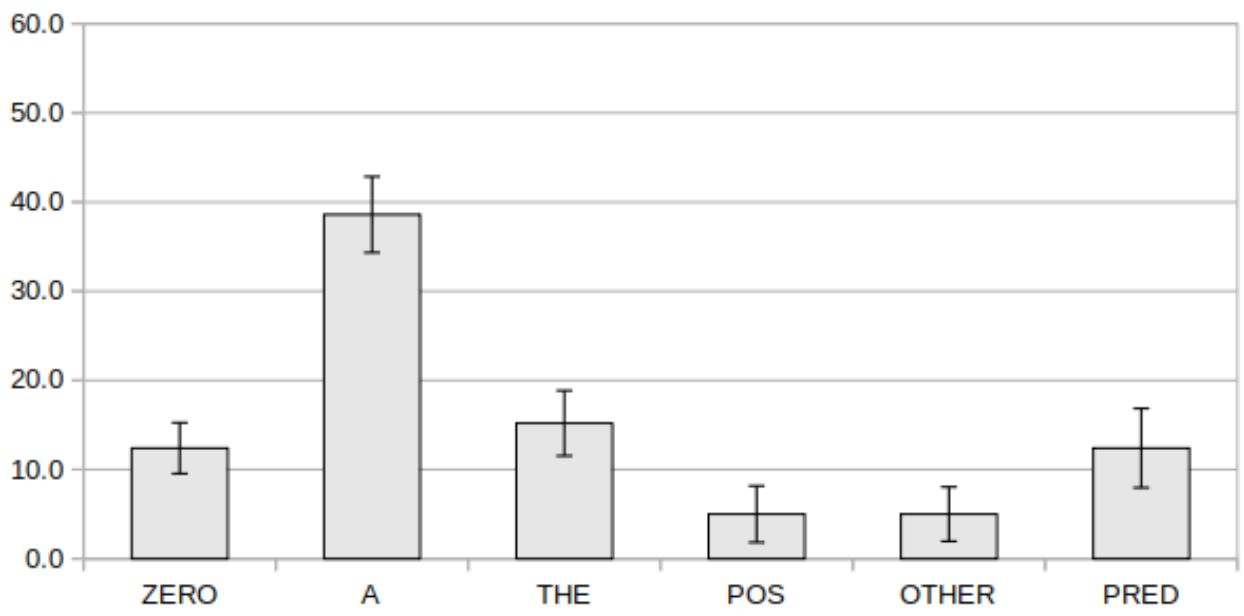

Figure 5. SMALL: Percentage of occurrences with most frequent determiners (Zero, Indefinite article "A(N)", Definite article "THE", Possessives, all others). Percentage of occurrences in predicative function

Syntactic distribution: SMALL

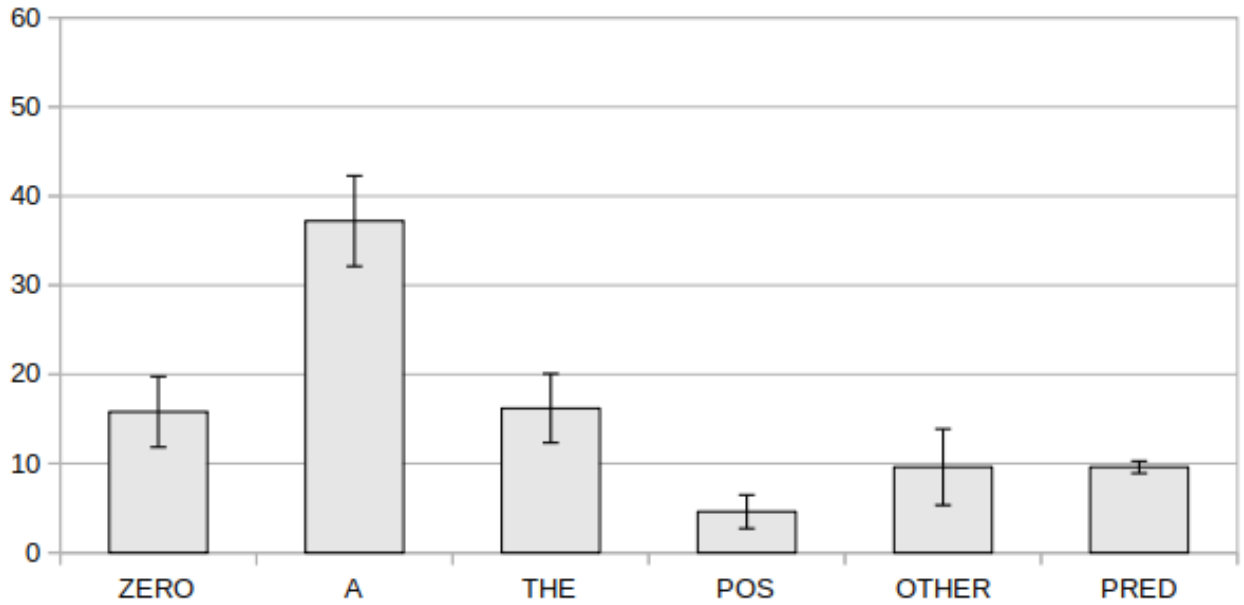


Figure 6. BIG: Percentage of occurrences with most frequent determiners (Zero, Indefinite article "A(N)", Definite article "THE", Possessives, all others). Percentage of occurrences in predicative function

\section{Syntactic distribution: BIG}

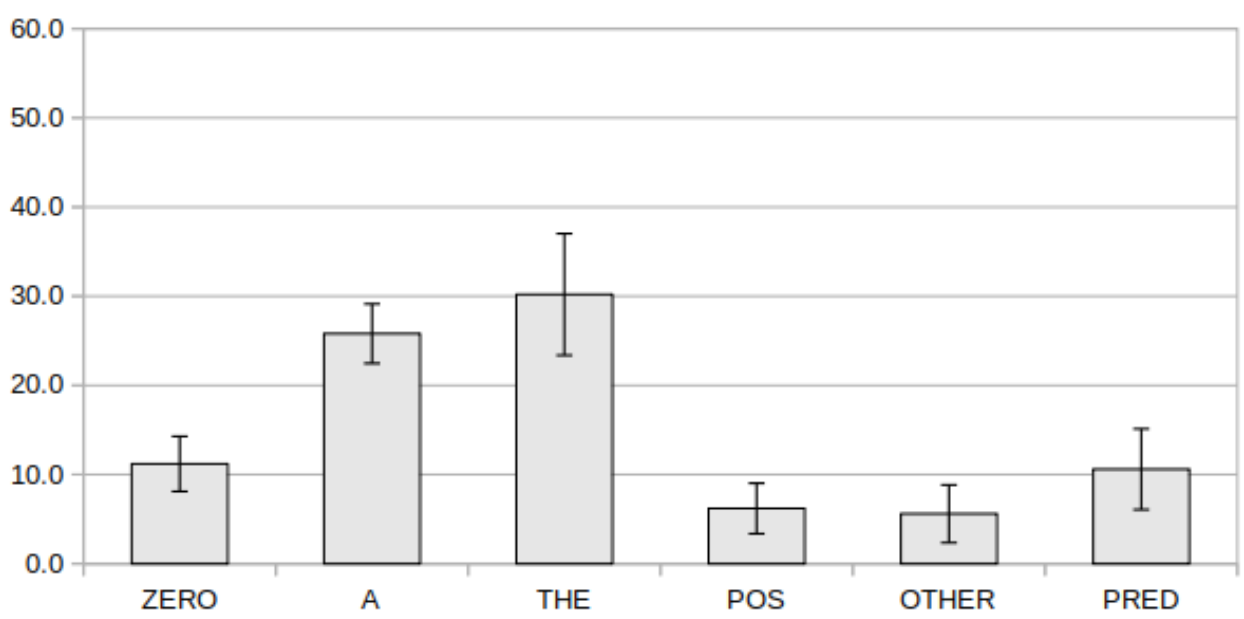

\subsubsection{Receptivity to intensifiers}

All three adjectives denoting size are highly receptive to intensifiers. Once again big presents a slightly different profile, being only slightly more susceptible to intensification than average when used adnominally, while its susceptibility in predicative function is such that it is used more often with some form of intensification than alone.

Table 9. Intensification and syntactic function: Adjectives of size (large, small, big). Percentage of occurrences containing marks of intensification ("large", "small", "big" vs. average values for the adjective category) according to syntactic function

\begin{tabular}{|l|l|l|l|l|}
\hline & large & small & big & category \\
\hline \% Intensifiers, all occurrences & 22.8 & 15.8 & 14.6 & 10.2 \\
\hline \% Intensifiers, adnominal & 15.2 & 11.7 & 7.4 & 5.5 \\
\hline \% Intensifiers, predicative & 42.4 & 36.4 & 54.7 & 18.9 \\
\hline
\end{tabular}

This receptivity to intensification is spread fairly evenly across all major intensifiers, with two exceptions: "large+comparative", which occurs with a much higher frequency (12.1\% of all occurrences of "large") than any other adjective+intensifier combination, and "very+big", which occurs less often than for adjectives in general.

Table 10. Intensifiers: Adjectives of size (large, small, big). Percentage of individual marks of intensification regardless of syntactic function ("large", "small", "big" vs. average values for the adjective category)

\begin{tabular}{|l|l|l|l|l|}
\hline & large & small & big & category \\
\hline
\end{tabular}




\begin{tabular}{|l|l|l|l|l|}
\hline comparative & $\mathbf{1 2 . 1}$ & 6.9 & 6.7 & $2.87(+0.75$ “more" = 3.62) \\
\hline superlative & 3.08 & 3.1 & 3.4 & $2.11(+0.59$ “most" = 2.70) \\
\hline very & 2.8 & 2.7 & $\mathbf{0 . 7}$ & 1.50 \\
\hline so & 3.35 & 2.1 & 1.9 & 1.59 \\
\hline too & 1.44 & 1.1 & 1.8 & 0.67 \\
\hline more & 0 & 0.0 & 0.1 & 0.75 \\
\hline most & 0 & 0.0 & 0.1 & 0.59 \\
\hline less & 0 & 0.0 & 0.0 & 0.14 \\
\hline least & 0 & 0.0 & 0.0 & 0.03 \\
\hline
\end{tabular}

From a distributional point of view, adjectives of size also form a coherent and distinctive class with similar syntactic predispositions and affinities: all are more strongly predisposed to adnominal function than the average for the category and highly receptive to all forms of intensification in both primary syntactic functions. Within this micro-class, however, big differs from the pair large/small, which present almost identical syntactic profiles in every respect, by its lack of affinity with any major determiner, and a paradoxical hyper-receptivity to intensification in predicative function but resistance to very. Although such an undertaking would be beyond the scope of this paper, in any model of the syntax-semantics interface that postulates even an imperfect correlation between syntax and semantics, each of these specific features is potentially an indicator of a divergence in the way size is conceptualized with big as opposed to large and small and therefore a perspective for further qualitative analysis.

\subsection{Adjectives denoting color. black, white, grey/gray, red, blue, yellow}

51 All adjectives denoting colors are predisposed to adnominal function by ratios of 8:1 or 10:1, are relatively resistant to intensification, except when used predicatively, and exhibit no particularly strong affinities with any determiner. Adnominal and predicative occurrences generally account for around $70-80 \%$ of their distribution, while a large proportion of the unclassified occurrences are nominalisations, as seen in the following examples:

(26) The burnished brown of the hard-wood trees, the dull carbon shadows of the evergreens, seemed to wither to one black as the red strengthened in the sky. (W.D. Howells, The Landlord at Lions Head)

(27) Where she stood the air was crystal clear, and she seemed to be looking out on a broad snow-field of purest white. (R. Barr, The Sword Maker)

(28) All her life she had held those imaginary conversations, but heretofore it had been with her horse, her dog, the trees, a white cloud against the blue, something somewhere. (S. Glaspell, The Visioning) 


\subsubsection{Adnominal/predicative predisposition}

52 Adjectives describing colors are again predisposed to adnominal function but only slightly more so than for the category as a whole:

Table 11. Adnominal vs. predicative predisposition: adjectives of color (black, white, grey/gray): percentage of adnominal and predicative occurrences estimated manually $(M)$ from 5 random samples of 100 occurrences and by regular expressions (R), vs. average for the adjective category

\begin{tabular}{|l|l|l|l|l|}
\hline & black & white & grey & category \\
\hline \multirow{2}{*}{ \% Adnominal } & M: $76( \pm 7.7)$ & M:70.2 $( \pm 4.8)$ & M: 70.6 $( \pm 7.5)$ & M: $64.8( \pm 7.5)$ \\
R: 71.4 & R: 69.1 & R: 71.0 & R: 62.3 \\
\hline \multirow{2}{*}{ \% Predicative } & M: $8.8( \pm 4.5)$ & M:8.4 $( \pm 1.9)$ & M: $8.2( \pm 2.8)$ & M: $16.8( \pm 5.2)$ \\
& R: 6.7 & R: 6.6 & R: 6.2 & R: 15.4 \\
\hline Total & M: 84.8 & M: 78.6 & M: 78.8 & M: 81.6 \\
& R: 78.0 & R: 75.8 & R: 77.2 & R: 77.7 \\
\hline
\end{tabular}

Table 12. Adnominal vs. predicative predisposition: adjectives of color (red, blue, yellow): percentage of adnominal and predicative occurrences estimated manually $(M)$ from 5 random samples of 100 occurrences and by regular expressions (R), vs. average for the adjective category

\begin{tabular}{|l|l|l|l|l|}
\hline & red & blue & yellow & category \\
\hline \multirow{2}{*}{ \% Adnominal } & $\begin{array}{l}\text { M: } 67( \pm 4.7) \\
\text { R: } 62.7\end{array}$ & $\begin{array}{l}\text { M: } 69.6( \pm 6.9) \\
\text { R: } 69.3\end{array}$ & $\begin{array}{l}\text { M: 73.6 ( } \pm 5.3) \\
\text { R: } 70.6\end{array}$ & $\begin{array}{l}\text { M: } 64.8( \pm 7.5) \\
\text { R: } 62.3\end{array}$ \\
\hline \multirow{2}{*}{ \% Predicative } & M: $13.8( \pm 3.4)$ & M: $5( \pm 2.2)$ & M: $8.6( \pm 5.2)$ & M: $16.8( \pm 5.2)$ \\
& R: 8.5 & R: 4.0 & R: 7.0 & R: 15.4 \\
\hline Total & M: 80.8 & M: 74.6 & M: 82.2 & M: 81.6 \\
& R: 71.16 & R: 73.27 & R: 77.69 & R: 77.7 \\
\hline
\end{tabular}

\subsubsection{Affinities with most frequent determiners}

53 None of these adjectives shows a strong affinity with any determiner, but all display a similar pattern of co-occurrence with most frequent determiners: the highest proportions are around $20 \%$ for the and zero, but in most cases the confidence intervals overlap with the indefinite article and/or possessives as well. 
Figure 7. BLACK: percentage of occurrences with most frequent determiners (Zero, Indefinite article "A(N)", Definite article "THE", Possessives, all others). Percentage of occurrences in predicative function

\section{Syntactic distribution: BLACK}

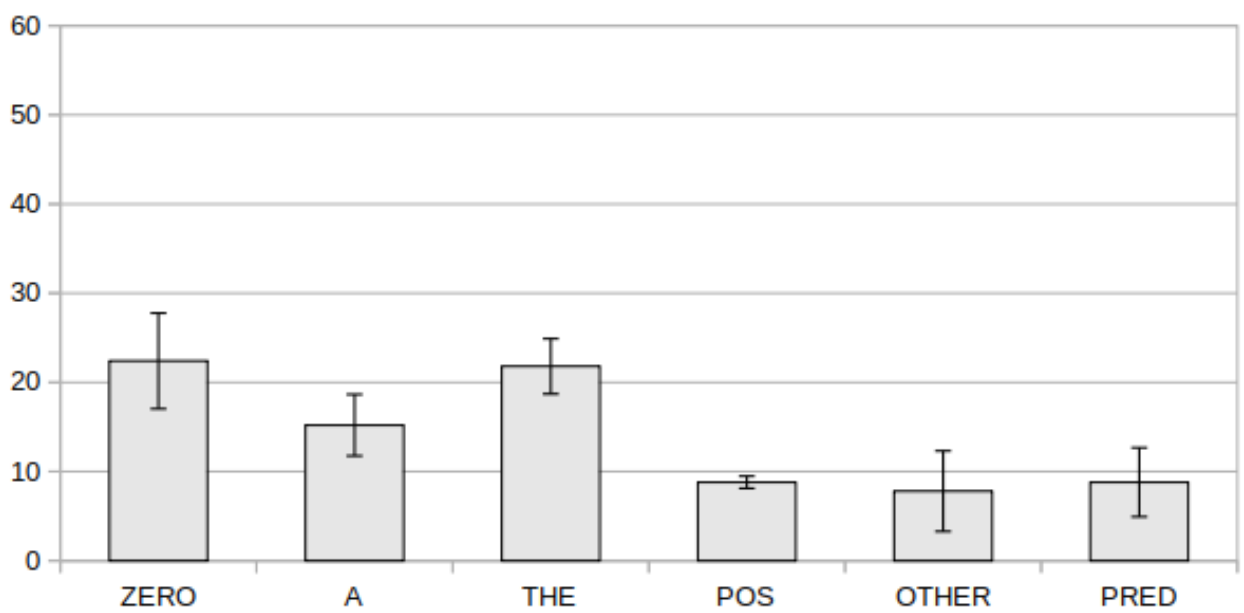

Figure 8. WHITE: percentage of occurrences with most frequent determiners (Zero, Indefinite article "A(N)", Definite article "THE", Possessives, all others). Percentage of occurrences in predicative function

\section{Syntactic distribution: WHITE}

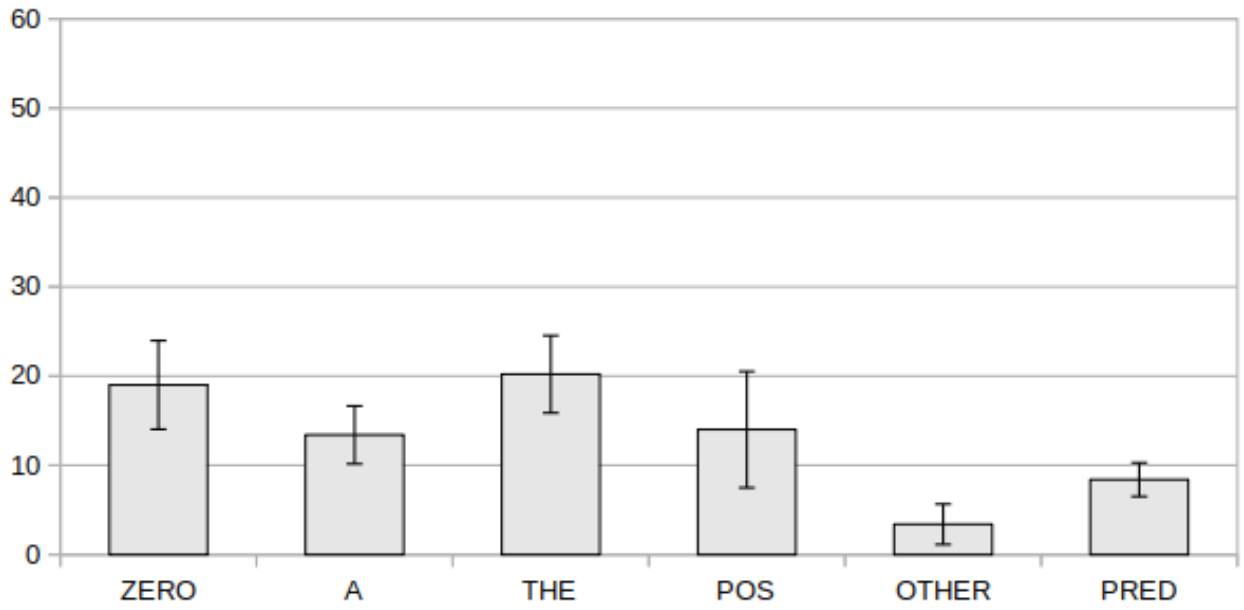


Figure 9. GREY/GRAY: percentage of occurrences with most frequent determiners (Zero, Indefinite article " $\mathrm{A}(\mathrm{N})$ ", Definite article "THE", Possessives, all others). Percentage of occurrences in predicative function

\section{Syntactic distribution: GRAY/GREY}

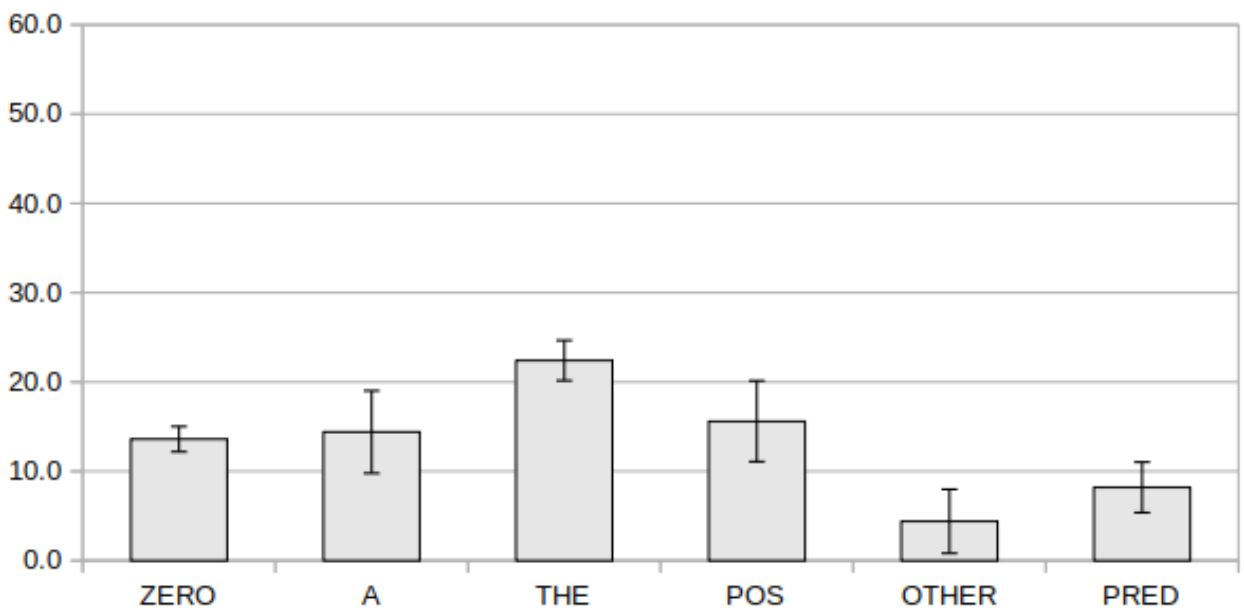

Figure 10. RED: percentage of occurrences with most frequent determiners (Zero, Indefinite article "A(N)", Definite article "THE", Possessives, all others). Percentage of occurrences in predicative function

Syntactic distribution: RED

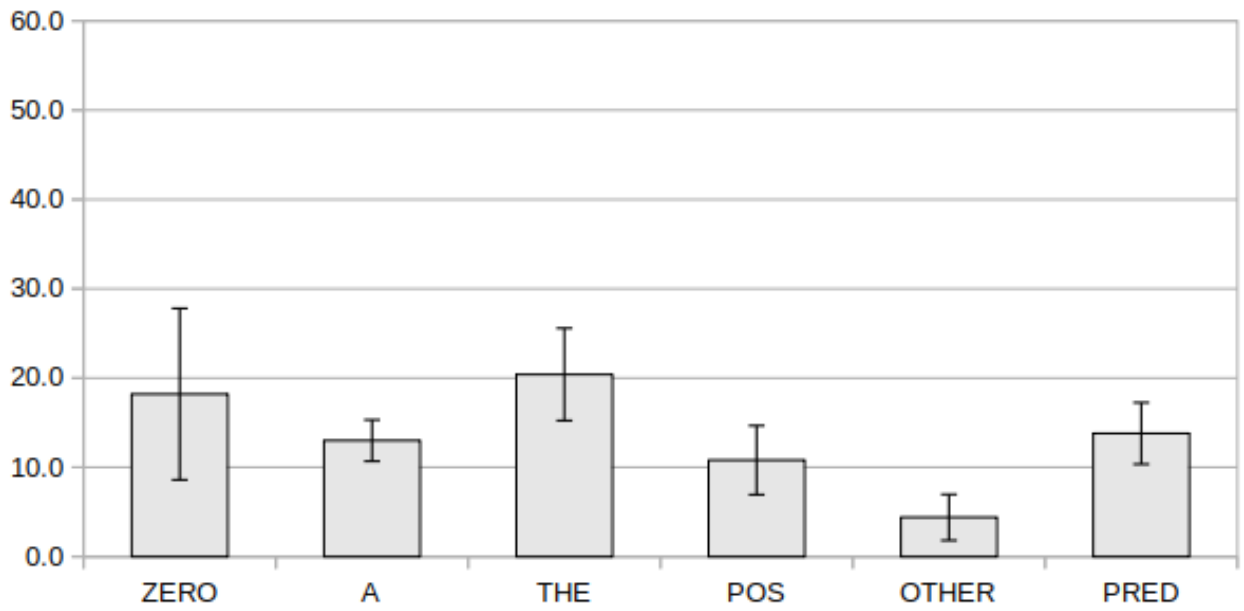


Figure 11. BLUE: percentage of occurrences with most frequent determiners (Zero, Indefinite article "A(N)", Definite article "THE", Possessives, all others). Percentage of occurrences in predicative function

\section{Syntactic distribution: BLUE}

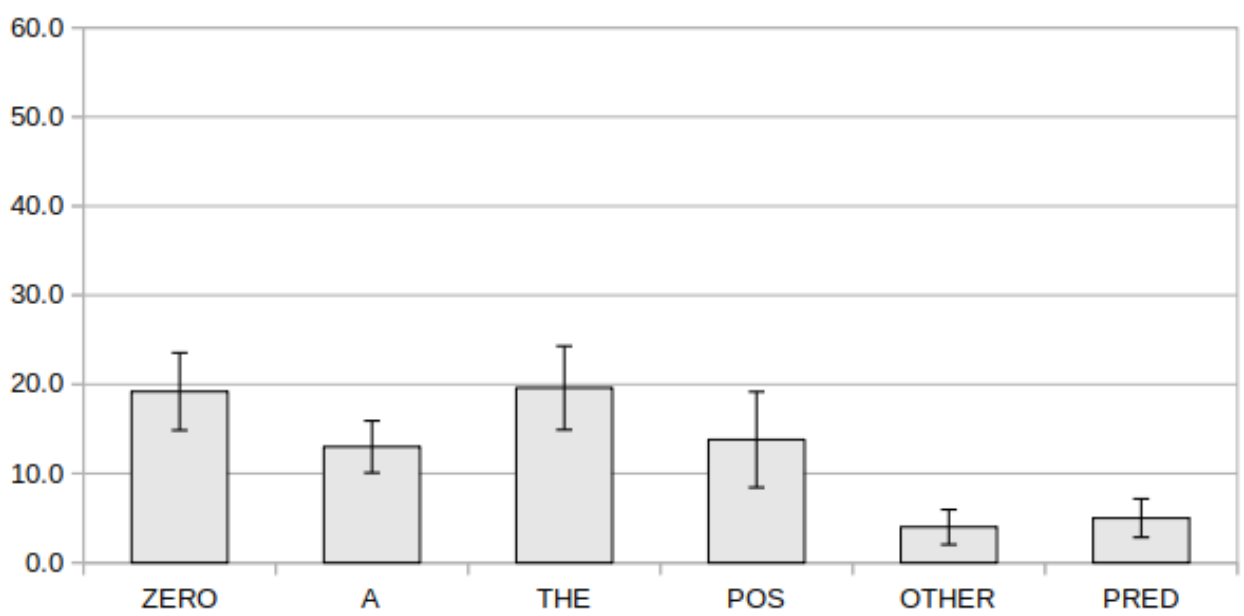

Figure 12. YELLOW: percentage of occurrences with most frequent determiners (Zero, Indefinite article " $\mathrm{A}(\mathrm{N})$ ", Definite article "THE", Possessives, all others). Percentage of occurrences in predicative function

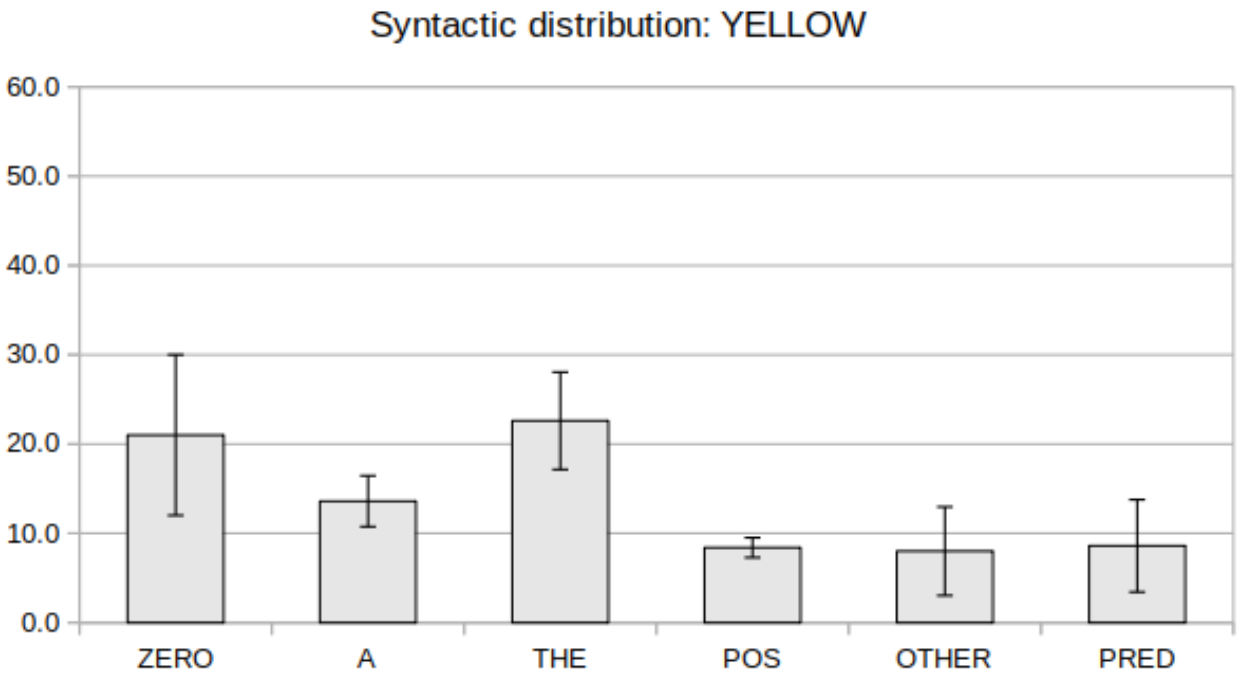

\subsubsection{Receptivity to intensifiers}

Adjectives denoting color are mostly resistant to intensification, except when used predicatively in which case black, white, red and blue take marks of intensification about as often as the overall average for the category. 
Table 13. Intensification and syntactic function: adjectives of color (black, white, grey/gray, red, blue, yellow). Percentage of occurrences containing marks of intensification (black, white, grey/ gray, red, blue, yellow vs. average values for the adjective category) according to syntactic function

\begin{tabular}{|l|l|l|l|l|l|l|l|}
\hline & black & white & grey & red & blue & yellow & category \\
\hline \% Intensifiers, all occurrences & 3.7 & 3.3 & 1.3 & 4.0 & 1.6 & 1.0 & 10.2 \\
\hline \% Intensifiers, adnominal & 1.8 & 0.6 & 0.2 & 1.0 & 0.5 & 0.6 & 5.5 \\
\hline \% Intensifiers, predicative & 18.4 & 16.8 & 10.2 & 19.8 & 20 & 2.8 & 18.9 \\
\hline
\end{tabular}

This resistance to intensification affects all major intensifiers, with the exception of the expression "very+red" (used most often when describing a person's face).

Table 14. Intensifiers: adjectives of color (black, white, grey/gray, red, blue, yellow). Percentage of individual marks of intensification regardless of syntactic function (black, white, grey, red, blue, yellow vs. average values for the adjective category)

\begin{tabular}{|l|l|l|l|l|l|l|l|}
\hline & black & white & grey & red & blue & yellow & category \\
\hline comparative & 1.6 & 0.8 & 0.64 & 1.32 & 0.34 & 0.2 & $2.87(+0.75$ “more" = 3.62) \\
\hline superlative & 0.6 & 0.3 & 0.13 & 0.18 & 0.23 & 0 & $2.11(+0.59$ "most" = 2.70) \\
\hline very & 0.7 & 1.1 & 0 & 1.59 & 0.34 & 0.2 & 1.50 \\
\hline so & 0.6 & 1.0 & 0.25 & 0.18 & 0.57 & 0 & 1.59 \\
\hline too & 0.1 & 0.1 & 0.13 & 0.44 & 0 & 0 & 0.67 \\
\hline more & 0.1 & 0.1 & 0.13 & 0.26 & 0.11 & 0.39 & 0.75 \\
\hline most & 0.0 & 0.0 & 0 & 0 & 0 & 0.2 & 0.59 \\
\hline less & 0.0 & 0.0 & 0 & 0 & 0 & 0 & 0.14 \\
\hline least & 0.0 & 0.0 & 0 & 0 & 0 & 0 & 0.03 \\
\hline
\end{tabular}

56 A distinctive common profile thus exists for adjectives of color as well. Syntactically, these adjectives are quite close to the prototype for the category, with a moderately strong predisposition to adnominal function and no affinities with most frequent determiners, their only distinctive characteristic being a resistance to intensification when used adnominally. It is interesting to note that of the six adjectives of color under study, those that are at opposite extremes of the scale of intensity, black and white, or at opposite ends of the color spectrum, blue and red, are most susceptible to intensification, while those that occupy the middle position, grey and yellow, are most resistant to it. Intensity, it may be surmised, is difficult to conceptualize in the middle zone. 


\subsection{Adjectives denoting modality: possible, impossible, necessary,}

\section{likely, sure}

Adjectives expressing concepts associated with epistemic modality are predisposed to predicative function in varying degrees. The type of subjects with which they are typically used, and the receptivity to intensification distinguish those that denote modality in a strictly logical sense, i.e. possible, impossible and necessary, from sure and likely, which express confidence or expectation.

\subsubsection{Adnominal/predicative predisposition}

With the exception of possible, modal adjectives are used predicatively in roughly twothirds of their occurrences:

Table 15. Adnominal vs. predicative predisposition: modal adjectives (possible, impossible, necessary). Percentage of adnominal and predicative occurrences estimated manually (M) from 5 random samples of 100 occurrences and by regular expressions (R), vs. average for the adjective category

\begin{tabular}{|l|l|l|l|l|}
\hline & possible & impossible & necessary & category \\
\hline \multirow{2}{*}{ \% Adnominal } & $\begin{array}{l}\text { M: } 20.2( \pm 4.6) \\
\text { R: } 22.0\end{array}$ & $\begin{array}{l}\text { M: } 6.2( \pm 4.2) \\
\text { R: } 5.2\end{array}$ & $\begin{array}{l}\text { M: } 14( \pm 5.3) \\
\text { R: } 14.2\end{array}$ & $\begin{array}{l}\text { M: } 64.8( \pm 7.5) \\
\text { R: } 62.3\end{array}$ \\
\hline \% Predicative & M: $39.2( \pm 3.7)$ & M: $65.8( \pm 3.4)$ & M: $63( \pm 4.0)$ & M: $16.8( \pm 5.2)$ \\
& R: 29.4 & R: 59.3 & R: 56.5 & R: 15.4 \\
\hline Total & M: 59.4 & M: 72 & M: 77 & M: 81.6 \\
& R: 51.4 & R: 64.5 & R: 70.8 & R: 77.7 \\
\hline
\end{tabular}

Table 16. Adnominal vs. predicative predisposition: modal adjectives (likely, sure). Percentage of adnominal and predicative occurrences estimated manually (M) from 5 random samples of 100 occurrences and by regular expressions $(R)$, vs. average for the adjective category

\begin{tabular}{|l|l|l|l|}
\hline & likely & sure & category \\
\hline \multirow{2}{*}{ \% Adnominal } & $\begin{array}{l}\text { M: } 3.6( \pm 2.1) \\
\text { R: } 4.7\end{array}$ & $\begin{array}{l}\text { M: } 3.4( \pm 2.3) \\
\text { R: } 5.4\end{array}$ & $\begin{array}{l}\text { M: } 64.8( \pm 7.5) \\
\text { R: } 62.3\end{array}$ \\
\hline \% Predicative & M: $68.4( \pm 6.0)$ & M: $65( \pm 4.8)$ & M: $16.8( \pm 5.2)$ \\
& R: 58.4 & R: 65.4 & R: 15.4 \\
\hline Total & M: 72 & M: 68.4 & M: 81.6 \\
& R: 63.08 & R: 70.8 & R: 77.7 \\
\hline
\end{tabular}

These two syntactic functions, however, only account for around $60-77 \%$ of the distribution of these adjectives, which can be explained in large part by their use in a certain number of fixed expressions and/or in object complement constructions. 


\subsubsection{Extra-adnominal/predicative uses of possible}

(29) I made up my mind, if possible, to probe the business to the bottom, then and there. (R. Marsh, The Beetle)

(30) She put it to herself as indelicately as possible, in the hope that her brain would cry, "Rubbish, you're a self-conscious fool!" (E.M. Forster, Howards End)

while object complements, like the following, represent another $7.2 \%( \pm 4.6)$ :

(31) His intellect had made servants and lures of his emotions and his heart, for even his every case in court had been won by easy and selfish command of all those feelings in mankind which make possible personal understanding. (G. Parker, The Right of Way)

Once added to the proportions of adnominal and predicative uses, these other uses bring the total to around $95 \%$ of all occurrences of possible.

\subsubsection{Extra-adnominal/predicative uses of impossible}

Adnominal and predicative occurrences account for around $72 \%$ of the distribution of impossible. Object complements like the following make up around $13 \%( \pm 2)$ :

(32) The result of this was that Newman found it impossible to convince him of certain time-honored verities. (H. James, The American)

(33) He was therefore the more grievously disappointed, when Wallace Carpenter made it impossible for him to do so. (S.E. White, The Blazed Trail)

while another $6.2 \%( \pm 3.2)$ are interjections or exclamations:

(34) "Impossible! Completely impossible!" said Argyle. "Man is a seeker, and except as such, he has no significance, no importance." (D.H. Lawrence, Aaron's Rod)

(35) "There are always fires after earthquakes," she muttered. "Impossible! Impossible!" (G.F.H. Atherton, The Sisters-in-Law)

In all, these four uses represent around $91 \%$ of the total occurrences of impossible.

\subsubsection{Extra-adnominal/predicative uses of necessary}

In addition to its adnominal and predicative uses, the adjective necessary occurs in object complement constructions about $8.6 \%( \pm 1.9)$ of the time:

(36) Give me your address, in case I should find it necessary to send for you. (H. MacGrath, The Puppet Crown)

while, similarly to possible, the expression if necessary accounts for another $5.6 \%( \pm 2.4)$ :

(37) Henry waited with his rifle ready. If necessary he would fire, and then dart away among the bushes. (J.A. Altsheler, The Scouts of the Valley) 
Once again, around $91 \%$ of the occurrences of necessary correspond to one of these four uses.

\subsubsection{Extra-adnominal/predicative uses of likely}

As with the other modal adjectives, likely is used frequently in object complement constructions which account for $8.2 \%( \pm 2.4)$ of its occurrences:

(38) "That is true," replied his mother, "but every year of peace makes war less likely [...]." (R. Connor, The Major)

Adverbial uses represent $9.2 \%( \pm 4.4)$ :

(39) Mr. King will be all right in a few minutes. That rifle-shot will likely bring his friends; if not, you are safe, now, anyway. (H.B. Wright, The Eyes of the World)

for a total of about $84.4 \%$, while interjections or elliptical utterances make up most of the remainder (many of which could arguably be counted as adverbial uses):

(40) "I wonder whether your brother-in-law made them." - "Very likely," said Newman; "if he did, you may be very sure they are well made." (H. James, The American)

\subsubsection{Extra-adnominal/predicative uses of sure}

In addition to adnominal and predicative occurrences, which represent $68.4 \%$ of the distribution of sure ( $3.4 \%$ and $65 \%$ respectively), adverbial uses like the following account for another $13.8 \%( \pm 5.1)$ :

(41) He had never before appreciated a plain hardwood floor with a couple of wolfskins; it sure beat all the carpets in creation. (J. London, Burning Daylight) (42) As he spoke he turned over another portion of the carpet, and there, sure enough, was a great crimson spill upon the square white facing of the old-fashioned floor. (A.C. Doyle, The Return of Sherlock Holmes).

Object complements, essentially comprised of the expression make sure (that) represent approximately $4.4 \%( \pm 1.1)$ :

(43) The lock was stiff to turn, and I tried the handle of the door to make sure that I had locked it properly. (A.J. Rees, The Hand in the Dark)

Around $86 \%$ of the occurrences of sure are thus accounted for by one of these four uses, with the expressions for sure and to be sure making up most of the remainder.

\subsubsection{Syntactic distribution, affinities with $1^{\text {st }}, 2^{\text {nd }}$ or $3^{\text {rd }}$ person subjects}

Given that modal adjectives are seldom used in noun phrases, it would be difficult to establish a strong affinity with any determiners. The only tendency that can be discerned in this regard is with possible and necessary, which appear to be used most often with the definite article in contexts like the following examples: 
(44) The following day, they would spend in town; purchasing an outfit of the necessary equipment and supplies, securing a burro, and attending to numerous odds and ends of business preparatory to their indefinite absence. (H.B. Wright, The Eyes of the World)

(45) She hurried down the lane toward the main trail, refusing to discuss with herself the possible consequence of what she was doing. (R. Connor, The Major)

The predominance of predicative occurrences of modal adjectives is readily apparent in Figure 13:

Figure 13. POSSIBLE: percentage of occurrences with most frequent determiners (Zero, Indefinite article " $A(N)$ ", Definite article "THE", Possessives, all others). Percentage of occurrences in predicative function

\section{Syntactic distribution: POSSIBLE}

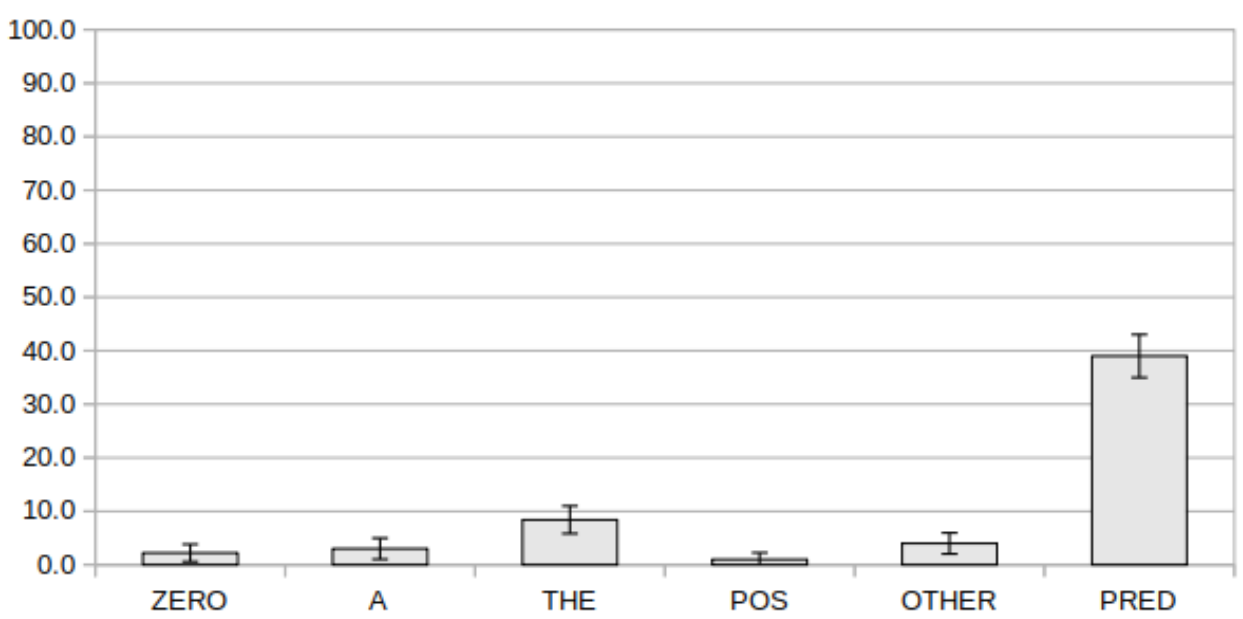

Figure 14. IMPOSSIBLE: percentage of occurrences with most frequent determiners (Zero, Indefinite article " $A(N)$ ", Definite article "THE", Possessives, all others). Percentage of occurrences in predicative function

\section{Syntactic distribution: IMPOSSIBLE}

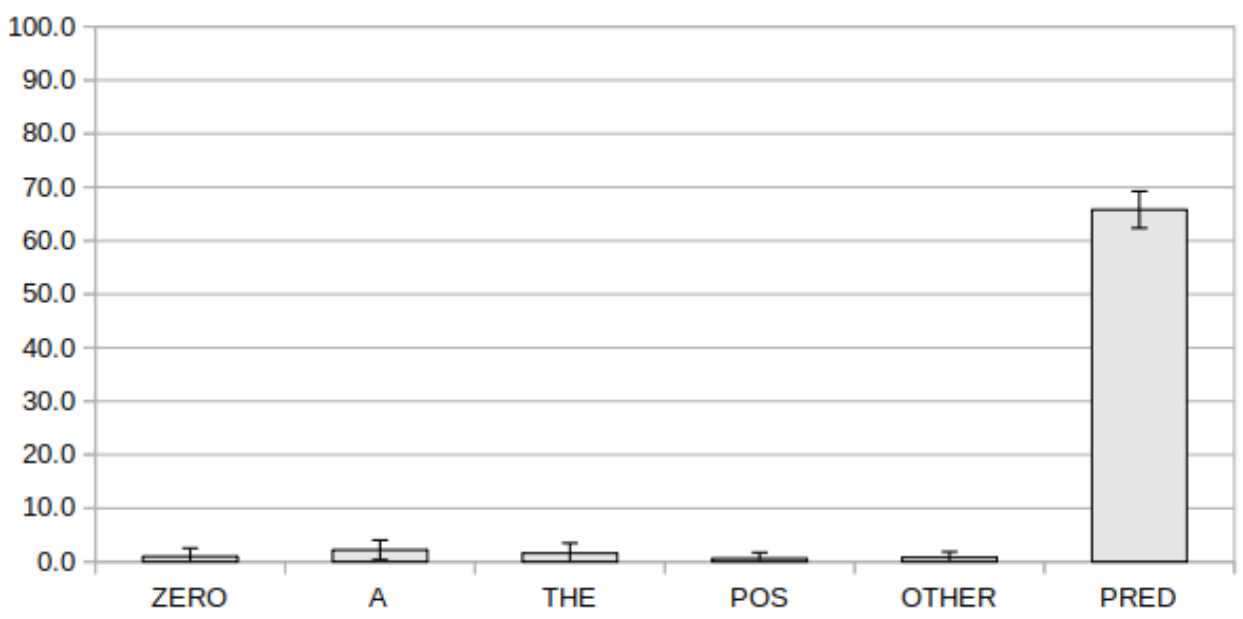


Figure 15. NECESSARY: percentage of occurrences with most frequent determiners (Zero, Indefinite article " $\mathrm{A}(\mathrm{N})$ ", Definite article "THE", Possessives, all others). Percentage of occurrences in predicative function

\section{Syntactic distribution: NECESSARY}

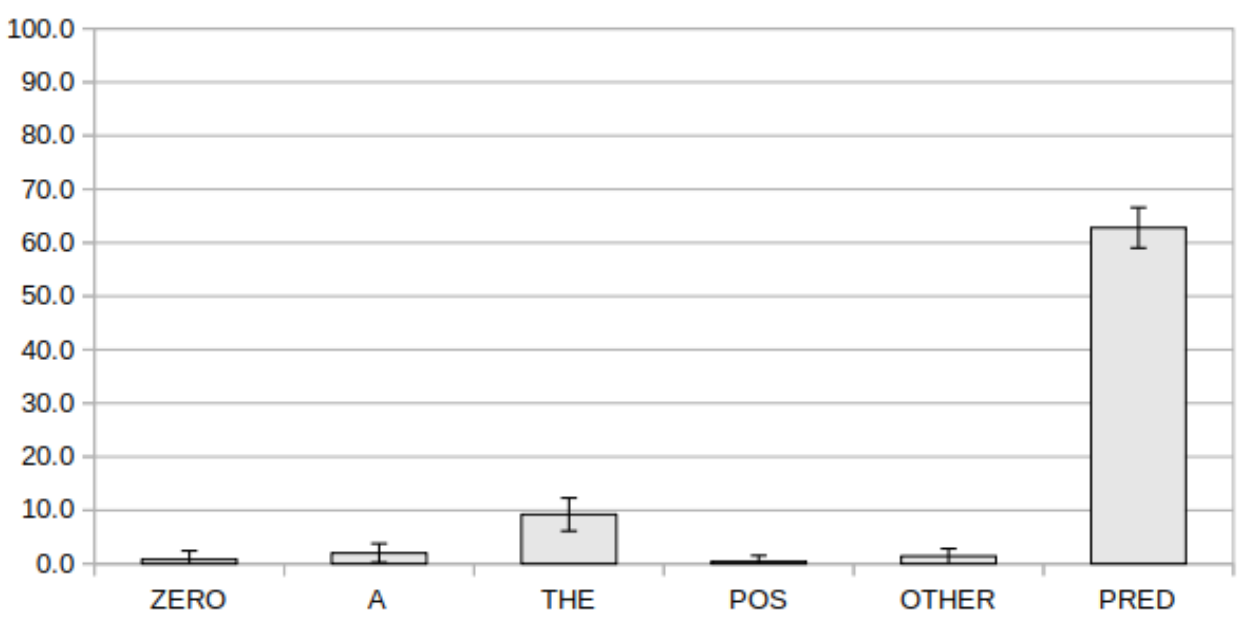

Figure 16. LIKELY: percentage of occurrences with most frequent determiners (Zero, Indefinite article " $\mathrm{A}(\mathrm{N})$ ", Definite article "THE", Possessives, all others). Percentage of occurrences in predicative function

\section{Syntactic distribution: LIKELY}

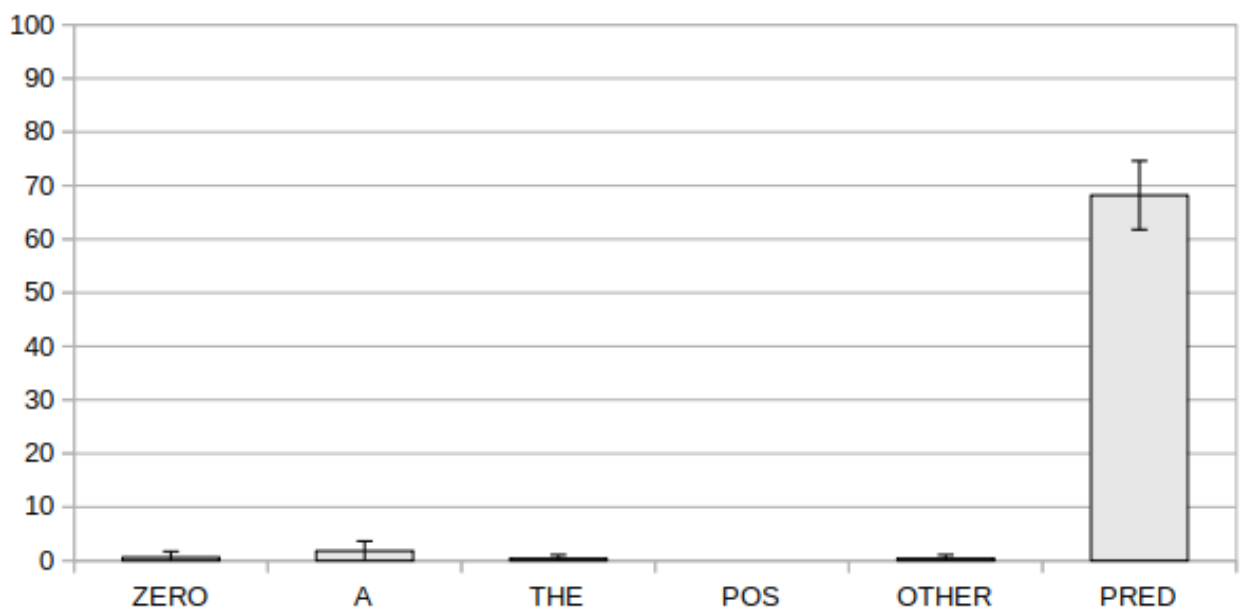


Figure 17. SURE: percentage of occurrences with most frequent determiners (Zero, Indefinite article " $\mathrm{A}(\mathrm{N})$ ", Definite article "THE", Possessives, all others). Percentage of occurrences in predicative function

\section{Syntactic distribution: SURE}

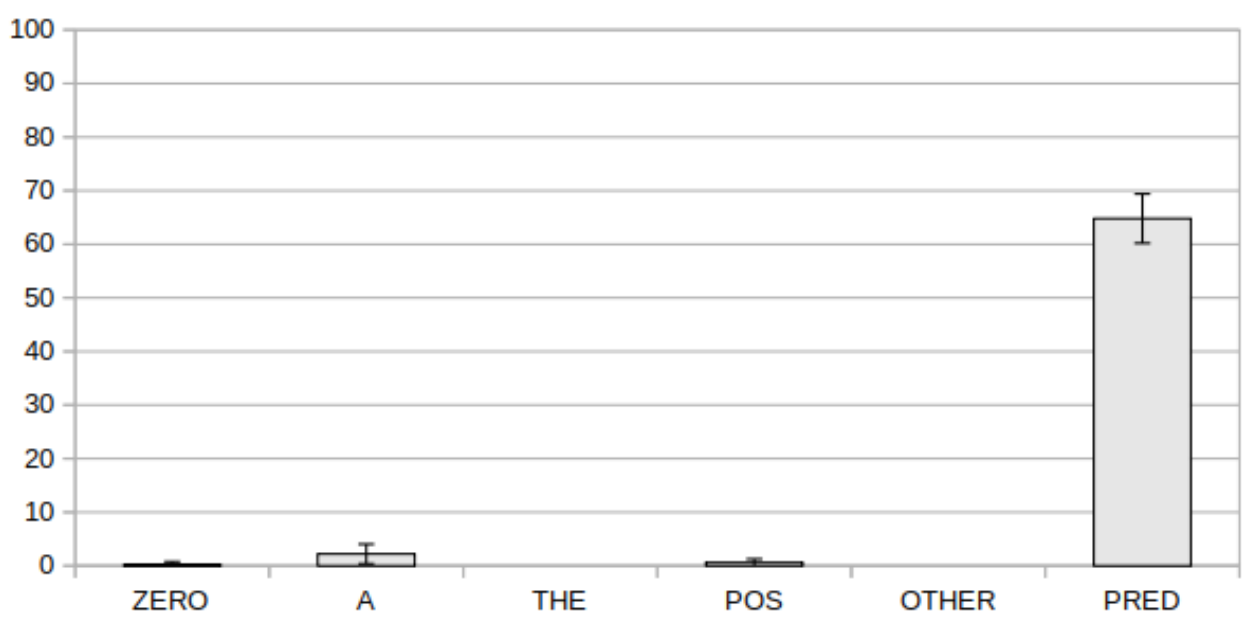

The types of subjects with which these are typically associated, however, reveal a difference between the logical modals, possible, impossible and necessary, as opposed to likely and sure. The former, rather unsurprisingly, occur almost exclusively with thirdperson subjects, most often it with an extraposed infinitive or that-clause, but occasionally with other pronouns or full noun phrases, as in (46)-(47):

(46) If the solution of the mystery lay near the scene, as he believed, it was possible that some clue might be picked up among the villagers [...]. (A.J. Rees, The Hand in the Dark)

(47) The weak point of his whole scheme lay in that it was going to be impossible for him to allow the prospective purchaser a chance of examining the pine. (S.E. White, The Blazed Trail)

(48) Curious; she has mistaken me for someone she does not know, if that is possible. (H. MacGrath, The Puppet Crown)

(49) "In these matters," Ruff answered, "my secretary does not exist apart from myself. Her presence is necessary. She takes down in shorthand notes of our conversation." (E.P. Oppenheim, Peter Ruff and the Double Four)

Table 17. Grammatical subjects: modal adjectives (possible, impossible, necessary, likely, sure). Percentage of occurrences with $1^{\text {st }}, 2^{\text {nd }}$ or $3^{\text {rd }}$ person subjects

\begin{tabular}{|l|l|l|l|l|l|}
\hline & possible & impossible & necessary & likely & sure \\
\hline I & $0( \pm 0)$ & $0( \pm 0)$ & $0.4( \pm 0.7)$ & $5.2( \pm 2.7)$ & $34.2( \pm 4.2)$ \\
\hline we & $0( \pm 0)$ & $0.4( \pm 0.7)$ & $0.6( \pm 1.1)$ & $3.2( \pm 2.7)$ & $10.4( \pm 4.4)$ \\
\hline you & $0( \pm 0)$ & $0.2( \pm 0.6)$ & $0( \pm 0)$ & $1.4( \pm 1.4)$ & $1( \pm 0.9)$ \\
\hline $3^{\text {rd }}$ p & $39.2( \pm 3.7)$ & $65.2( \pm 3.7)$ & $62( \pm 5.1)$ & $58.6( \pm 3.8)$ & $19.4( \pm 3.1)$ \\
\hline \% Pred. (total) & 39.2 & 65.8 & 63 & 68.4 & 65.0 \\
\hline
\end{tabular}


Adjectives which express an attitude of certainty or expectation are more often used with personal subjects:

(50) 'He's drunk,' replied Vandeloup, curtly, 'and he's likely to keep the game up for a week.' (F. Hume, Madame Midas)

(51) He asked to bring a friend of his with him, a Mr. Meyer, whom I do not know at all; but he is sure to be interesting if he is a friend of Professor Schaefer's. (R. Connor, The Major)

The adjective sure, in particular, distinguishes itself from the all the others by its affinity with first-person subjects, a characteristic it shares with adjectives describing mental states as will be seen in the following section:

(52) 'I'm sure he's better,' said the little doctor from Poitiers; 'I'm sure he'll come back.' (H. James, The American)

This versatility can be understood as a syntactic consequence of its capacity to express two complementary points of view (i.e. 'enantiosemy'), that of possessing certainty (" $I$ am sure he'll come back") or that of giving certainty ("he is sure to be interesting"):

$\left(49^{\prime}\right)$ he is sure to be interesting. >> I'm sure he is/will be interesting.

(50') I'm sure he'll come back. >> He's sure to come back.

\subsubsection{Receptivity to intensifiers}

81 Adjectives expressing logical modality are highly resistant to intensification of any sort both in adnominal and predicative function. In contrast, both likely and sure, when used adnominally, take marks of intensification almost two to three times more often than the overall average for the category (though due to the rarity of adnominal occurrences the total number nonetheless remains quite small), and they are more susceptible to intensification than possible, impossible or necessary in predicative function, albeit less so than adjectives in general.

Table 18. Intensification and syntactic function: modal adjectives (possible, impossible, necessary, likely, sure). Percentage of occurrences containing marks of intensification (possible, impossible, necessary, likely, sure vs. average values for the adjective category) according to syntactic function

\begin{tabular}{|l|l|l|l|l|l|l|}
\hline & possible & impossible & necessary & likely & sure & category \\
\hline \% Intensifiers, all occurrences & 1.5 & 1.8 & 2.3 & 19.2 & 7.6 & 10.2 \\
\hline \% Intensifiers, adnominal & 1.1 & 2.9 & 2.7 & 9.4 & 14.1 & 5.5 \\
\hline \% Intensifiers, predicative & 3.0 & 1.0 & 1.7 & 12.2 & 7.8 & 18.9 \\
\hline
\end{tabular}

With one exception, comparative and superlative forms are the only marks of intensification found in the minority of occurrences where likely and sure are used adnominally:

(53) It is a very sure tie between us. (R. Kipling, Kim) 
(54) But there is another and likelier way by which the murderer might have escaped. (A.J. Rees, The Hand in the Dark)

(55) The Street called Straight is often a crooked one; and yet it's the surest and safest route we can take from point to point. (B. King, The Street Called Straight)

\section{well as very, all of which occur in much higher proportions than the overall average: \\ (56) But Dwight had insisted that he was more likely to succeed in a business he understood than in one of which he knew nothing [...]. (G.F.H. Atherton, The Sisters-in-Law) \\ (57) "But I suppose," she began again, "he wouldn't be very likely to be there mending boats now?" (S. Glaspell, The Visioning)}

Almost all forms of intensification can be found among the predicative occurrences of sure, but only so occurs with greater than average frequency:

(58) They don't seem to think there is a particle of doubt they could put the world to rights, and things are so intricate - so confused - I don't see how they can be so sure they're saying the final word. (S. Glaspell, The Visioning)

Table 19. Intensifiers: Modal adjectives (possible, impossible, necessary, likely, sure). Percentage of individual marks of intensification regardless of syntactic function (possible, impossible, necessary, likely, sure vs. average values for the adjective category)

\begin{tabular}{|l|l|l|l|l|l|l|}
\hline & possible & impossible & necessary & likely & sure & category \\
\hline comparative & 0 & 0 & 0 & 0.15 & 0.92 & $2.87(+0.75$ "more" = 3.62) \\
\hline superlative & 0 & 0 & 0 & 0.44 & 0.38 & $2.11(+0.59$ “most" = 2.70) \\
\hline very & 0.73 & 0 & 0.38 & 5.52 & 1.56 & 1.50 \\
\hline so & 0 & 0.9 & 0.77 & 0 & 3.55 & 1.59 \\
\hline too & 0.08 & 0 & 0 & 0 & 0.65 & 0.67 \\
\hline more & 0.32 & 0.6 & 0.58 & 4.94 & 0.42 & 0.75 \\
\hline most & 0 & 0.15 & 0.38 & 6.25 & 0.15 & 0.59 \\
\hline less & 0 & 0.15 & 0.19 & 1.45 & 0 & 0.14 \\
\hline least & 0.24 & 0 & 0 & 0.44 & 0 & 0.03 \\
\hline
\end{tabular}

While all adjectives denoting modal concepts are predisposed to predicative function, two distinct profiles can be discerned: possible, impossible and necessary, i.e. those that can be defined logically as a quantification of scenarios or outcomes in possible worlds (necessary $=100 \%$ of all outcomes/scenarios, impossible $=0 \%$ of scenarios/outcomes, possible $>0 \%<100 \%$ of scenarios/outcomes), which are highly resistant to intensification and strongly associated with third-person subjects and extraposed infinitives or thatclauses in particular, while sure and likely, which express confidence or expectation 
(perhaps more accurately termed "para-modal" concepts) are more receptive to intensification and more compatible with personal subjects, especially sure.

\subsection{Adjectives denoting emotions or attitudes: glad, happy, sorry, sad}

Although their meanings might at first seem similar, the pairs of parasynonyms glad/ happy and sorry/sad have almost completely different syntactic profiles.

\subsubsection{Adnominal/predicative predisposition}

The pair glad and sorry are overwhelmingly predisposed to predicative function, while happy and sad present a more balanced profile in which adnominal occurrences represent around $25-50 \%$ of the total, a consequence of the frequent polysemic shifts in meaning to which both adjectives lend themselves, from that of perceiving an emotion, as in (59)-(60), to revealing an emotion, as in (61)-(63), or causing an emotion, as in (64)(66):

(59) "That is right. There are going to be too many sad people about for us to go crying and making them feel worse," said Larry. (R. Connor, The Major)

(60) Elnora was a happy girl as she hurried home to thank her mother. She was happy over her books that night, and happy all the way to school the following morning. (G. Stratton-Porter, A Girl of the Limberlost)

(61) Then the happy laughter of the young onlookers reassured him. (P.G. Wodehouse, Mike)

(62) He kept to himself the remainder of that day, [...] and at sunset he went to a lonely spot on the verge of the valley, where with sad eyes he watched the last rays of sunlight fade over the blackened hills. (Z. Grey, The Desert of Wheat)

(63) But Clayton surmised a relief behind his regret, and in the train the boy's eyes were happier than they had been for months. (M.R. Rinehart, Dangerous Days)

(64) The baroness, as I have said, drew Josephine aside, and tried to break to her the sad news: but her own grief overcame her [...]. (C. Reade, White Lies)

(65) His reminiscences were very happy of those days of cheerful contrivance, of her eager desire to make the tiny appartement a home to her boy [...] (C.M. Yonge, Nuttie's Father)

(66) The singing voice was sweet, penetrating, and thrilling, and the song was sad. (J.A. Altsheler, The Scouts of the Valley)

Similar examples, though not impossible, are found much less commonly with glad and sorry and seem to be largely restricted to fixed expressions or longstanding conventional collocations:

(67) So that very evening, while Nuttie only ventured on sharing with Annaple the glad tidings that Mr. Dutton was accepted, [...] Mark was almost stunned by the news, confirmed to him by Mr. Dutton as well as his uncle, that he was to be acknowledged as heir of Bridgefield Egremont [...]. (C.M. Yonge, Nuttie's Father)

(68) Time was when the lumber-jack who had the misfortune to fall sick or to meet with an accident was in a sorry plight indeed. (S.E. White, The Blazed Trail) 
Table 20. Adnominal vs. predicative predisposition: adjectives of emotion/attitude (happy, glad, sad, sorry). Percentage of adnominal and predicative occurrences estimated manually (M) from 5 random samples of 100 occurrences and by regular expressions (R), vs. average for the adjective category

\begin{tabular}{|l|l|l|l|l|l|}
\hline & happy & glad & sad & sorry & category \\
\hline \multirow{2}{*}{ \% Adnominal } & $\begin{array}{l}\text { M: } 25.2( \pm 7.5) \\
\text { R: } 26.4\end{array}$ & $\begin{array}{l}\text { M: } 3.6( \pm 1.4) \\
\text { R: } 4.9\end{array}$ & $\begin{array}{l}\text { M: } 50( \pm 9.1) \\
\text { R: } 47.5\end{array}$ & $\begin{array}{l}\text { M: } 4( \pm 3.6) \\
\text { R: } 4.6\end{array}$ & $\begin{array}{l}\text { M: } 64.8( \pm 7.5) \\
\text { R: } 62.3\end{array}$ \\
\hline \multirow{2}{*}{ \% Predicative } & M: $55.2( \pm 5.1)$ & M: $87.2( \pm 3.3)$ & M: $37.2( \pm 5.1)$ & M: $85( \pm 5.8)$ & M: $16.8( \pm 5.2)$ \\
& R: 45.5 & R: 79.8 & R: 27.1 & R: 78.0 & R: 15.4 \\
\hline Total & M: 80.4 & M: 90.8 & M: 87.2 & M: 89.0 & M: 81.6 \\
& R: 71.8 & R: 84.6 & R: 74.5 & R: 82.6 & R: 77.7 \\
\hline
\end{tabular}

The two primary syntactic functions only account for around $80 \%$ of the distribution of happy, which, like other predominantly predicative adjectives, is found in object complement constructions about $10.2 \%( \pm 1.8)$ of the time, essentially with two verbs, in "make happy" and "see happy". Around 4.4\% ( \pm 3.7$)$ of the occurrences of sad are object complements as well:

(69) I'm not such a beast! - I'd sooner see her happy than anything else in all the world. (R. Marsh, The Beetle)

(70) He answered her smile, as if she were a child whose determined kindness made him both happy and sad. (Z. Grey, The Desert of Wheat)

With glad and sorry, although occasional object complement constructions can be found, most of the unclassified occurrences are elliptical:

(71) "Glad I don't have to do that every day!" he commented, wiping his brow with the back of his wrist. (S.E. White, The Blazed Trail)

(72) Don't get sore; all ships are alike - we have to talk about something.

Sorry I can't help you with the shirt question. (R.E. Beach, The Ne'er-do-well)

\subsubsection{Syntactic distribution, affinities with most frequent determiners and $1^{\text {st }}, 2^{\text {nd }}$ or $3^{\text {rd }}$ person subjects}

91 Noun phrases containing sad take indefinite articles more often than all other most frequent determiners combined, although the confidence interval of $\pm 8.5 \%$ entails a certain amount of uncertainty as to the real strength of this association. Given their overwhelming predisposition to predicative function, none of the other adjectives denoting emotional states occurs often enough in adnominal function to show an affinity with any determiner. 
Figure 18. HAPPY: percentage of occurrences with most frequent determiners (Zero, Indefinite article "A(N)", Definite article "THE", Possessives, all others). Percentage of occurrences in predicative function

\section{Syntactic distribution: HAPPY}

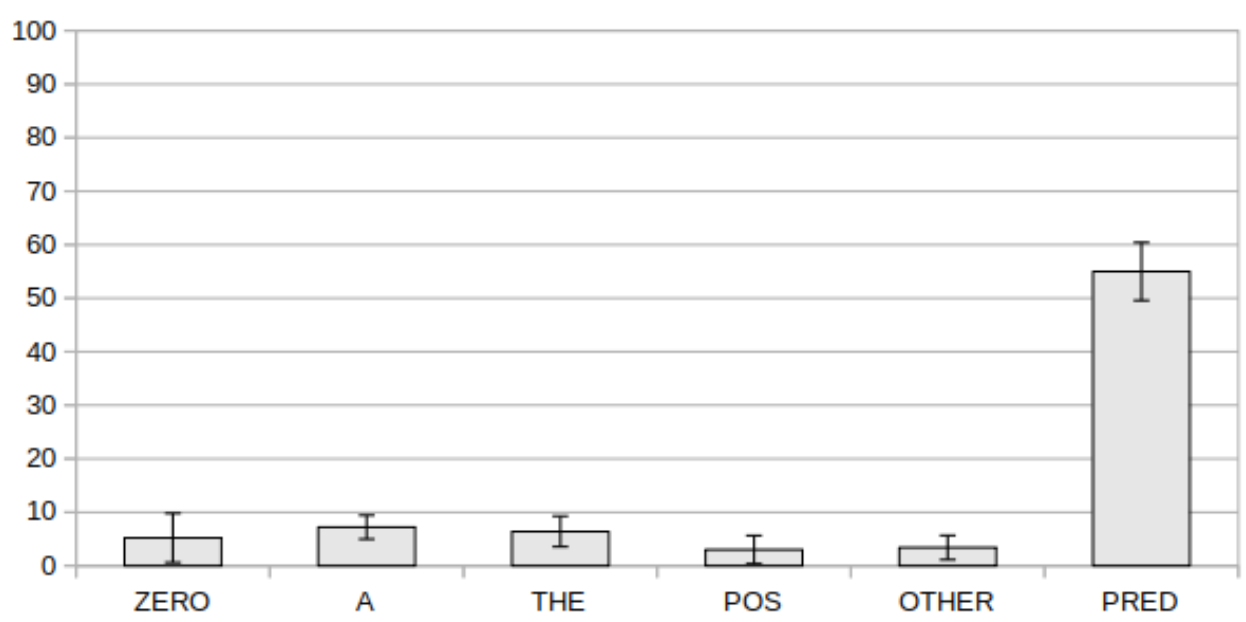

Figure 19. GLAD: percentage of occurrences with most frequent determiners (Zero, Indefinite article "A(N)", Definite article "THE", Possessives, all others). Percentage of occurrences in predicative function

\section{Syntactic distribution: GLAD}

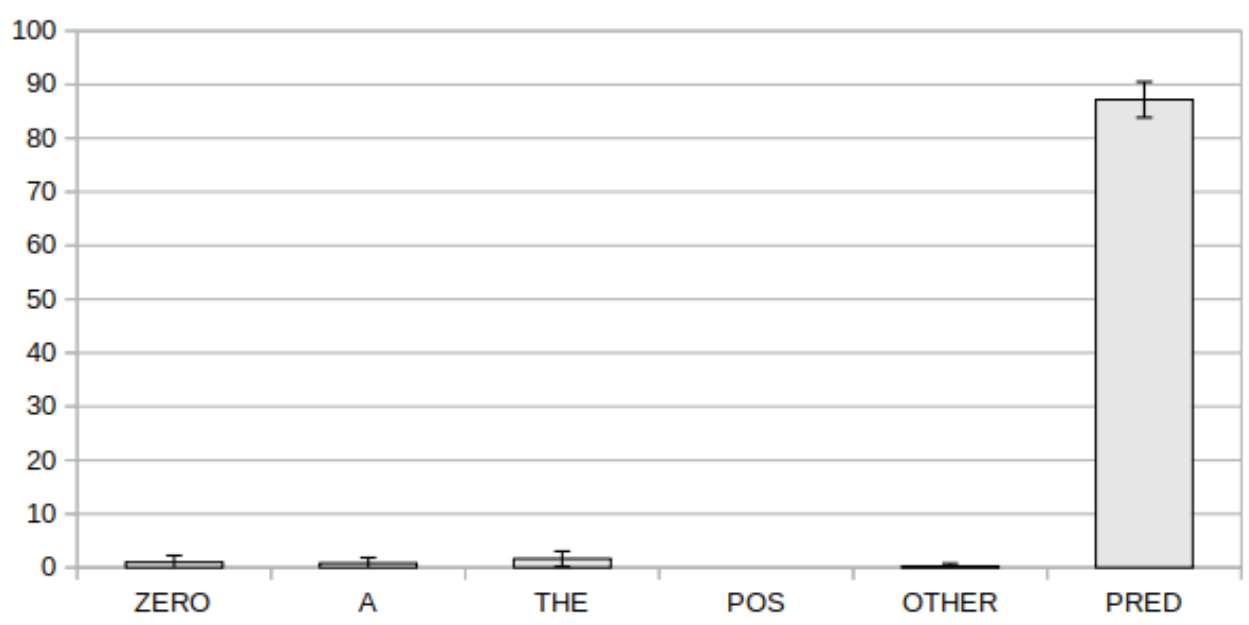


Figure 20. SAD: percentage of occurrences with most frequent determiners (Zero, Indefinite article "A(N)", Definite article "THE", Possessives, all others). Percentage of occurrences in predicative function

\section{Syntactic distribution: SAD}

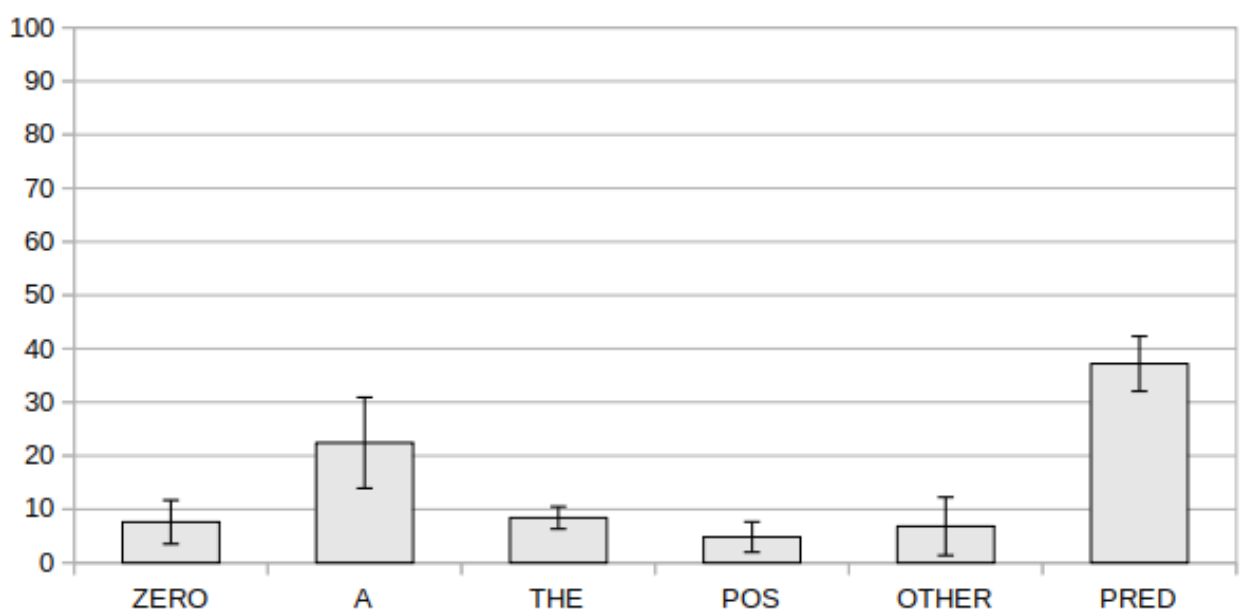

Figure 21. SORRY: percentage of occurrences with most frequent determiners (Zero, Indefinite article " $\mathrm{A}(\mathrm{N})$ ", Definite article "THE", Possessives, all others). Percentage of occurrences in predicative function

\section{Syntactic distribution: SORRY}

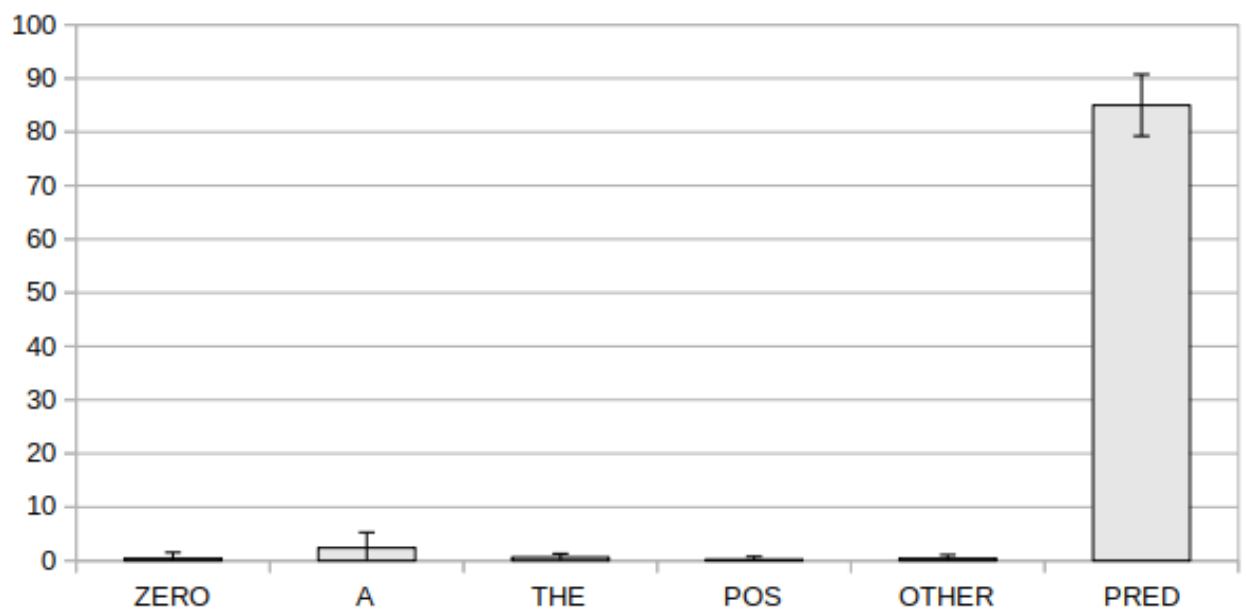

Despite the fact that the narrative discourse type inherently favors the use of the thirdperson, which is the most common subject type for happy and sad, glad and sorry nonetheless both exhibit a strong affinity with first-person subjects, which are over twice as frequent as third-person subjects with these two adjectives:

Table 21. Grammatical subjects: adjectives of emotion/attitude (happy, glad, sad, sorry). Percentage of occurrences with $1^{\text {st }}, 2^{\text {nd }}$ or $3^{\text {rd }}$ person subjects

\begin{tabular}{|l|l|l|l|l|}
\hline & happy & glad & sad & sorry \\
\hline I & $16( \pm 4.7)$ & $53.2( \pm 7.3)$ & $3.2( \pm 3.3)$ & $52.4( \pm 6.1)$ \\
\hline
\end{tabular}




\begin{tabular}{|l|l|l|l|l|}
\hline we & $8.6( \pm 4.2)$ & $3.6( \pm 2.1)$ & $2( \pm 2.5)$ & $7.6( \pm 4.9)$ \\
\hline you & $4( \pm 1.5)$ & $3.4( \pm 1.9)$ & $0( \pm 0)$ & $0.6( \pm 1.1)$ \\
\hline $3^{\text {rd }} \mathbf{p}$ & $26.6( \pm 4.3)$ & $27( \pm 9.9)$ & $32( \pm 6.3)$ & $24.4( \pm 4.5)$ \\
\hline \% Pred. (total) & 55.2 & 87.2 & 37.2 & 85.0 \\
\hline
\end{tabular}

The preponderance of first-person, i.e. deictic, subjects with glad/sorry can be seen as a corollary of the kind of attitude expressed by these two adjectives which, in contrast with the more enduring sentiments conveyed by happy and sad, is situationally dependent, i.e. contingent on a particular circumstance, ${ }^{7}$ often with an added dimension of empathy and/or pragmatic implicatures such as asking for or receiving pardon:

(73) And, though I'm glad he's better in health, I'm sorry he's so much less pleasant, and so much less affectionate to me. (E. Brontë, Wuthering Heights)

(74) Well, Mr Atherton, I am sorry to be obliged to leave you. I have enjoyed my visit very much. I only hope I have not seemed too intrusive. (R. Marsh, The Beetle)

(75) You've got her, have you? Well, I'm glad of it, old man. I am, for a fact. I know you'll be happy with her. I know how I would have been. I forgive you; yes, I forgive you, freely. (F. Norris, McTeague)

\subsubsection{Receptivity to intensifiers}

In terms of overall receptivity to intensification the pair happy/sad are more receptive in predicative function than are glad/sorry, while happy is the only adjective in the series that shows a higher receptivity to intensification overall in both primary syntactic functions, but otherwise no real pattern can be said to emerge from the data.

Table 22. Intensification and syntactic function: adjectives of emotion/attitude (happy, glad, sad, sorry). Percentage of occurrences containing marks of intensification (happy, glad, sad, sorry vs. average values for the adjective category) according to syntactic function

\begin{tabular}{|l|l|l|l|l|l|}
\hline & happy & glad & sad & sorry & category \\
\hline \% Intensifiers, all occurrences & 24.5 & 17.9 & 16.1 & 15.1 & 10.2 \\
\hline \% Intensifiers, adnominal & 16.1 & 3.1 & 4.3 & 2.5 & 5.5 \\
\hline \% Intensifiers, predicative & 29.5 & 18.9 & 25.4 & 15.8 & 18.9 \\
\hline
\end{tabular}

The most obvious difference between the pairs happy/sad and glad/sorry is the resistance of the latter pair to comparative and superlative forms, whereas happy and sad take all major marks of intensification at a higher than average frequency. 
Table 23. Intensifiers: adjectives of emotion/attitude (happy, glad, sad, sorry). Percentage of individual marks of intensification regardless of syntactic function (happy, glad, sad, sorry vs. average values for the adjective category)

\begin{tabular}{|l|l|l|l|l|l|}
\hline & happy & glad & sad & sorry & category \\
\hline comparative & 6.35 & $\mathbf{0 . 3}$ & 2.75 & $\mathbf{0 . 6 8}$ & $2.87(+0.75$ “more" = 3.62) \\
\hline superlative & 2.98 & $\mathbf{0 . 1 5}$ & 2.75 & $\mathbf{0}$ & $2.11(+0.59$ “most" = 2.70) \\
\hline very & 5.88 & 7.76 & 5.28 & 7.41 & 1.50 \\
\hline so & 6.98 & 7.46 & 3.9 & 5.82 & 1.59 \\
\hline too & 1.18 & 1.72 & 0.92 & 0.23 & 0.67 \\
\hline more & 0.31 & 0.45 & 0 & 0.46 & 0.75 \\
\hline most & 0.78 & 0 & 0.46 & 0.11 & 0.59 \\
\hline less & 0.08 & 0.07 & 0 & 0.23 & 0.14 \\
\hline least & 0 & 0 & 0 & 0.11 & 0.03 \\
\hline
\end{tabular}

Adjectives describing attitudes or emotions thus present a syntactic profile which distinguishes them from adjectives in general, as well as other predominantly predicative adjectives such as modal adjectives. These adjectives have a moderate to strong predisposition to predicative function, a tendency which is much more pronounced with glad/sorry than happy/sad. Unlike modal adjectives, they are highly receptive to intensification and (unsurprisingly) typically associated with personal subjects. The pairs happy/sad and glad/sorry can furthermore be shown to differ from one another in that the former are more ambivalent both semantically and syntactically, with the capacity to express alternative meanings in both primary syntactic functions ("a happy girl", "she was happy", "with sad eyes" "the boy's eyes were happier", "the song was sad"), while the latter are specialized in expressing the perception of a transient feeling, most often related to a specific situation and/or in regard to another person, in predicative function, with a much more limited capacity to function adnominally.

\section{Conclusion}

Firth's famous maxim "You shall know a word by the company it keeps" (Firth [1968: 179]), often taken as an epitome for the distributionalist approach, was first formulated with reference to collocations, i.e. lexical associations, but this study has shown that words reveal themselves in context through their syntactic affinities as well. The parallelism that has been demonstrated between intuitively recognizable semantic classes and syntactic profiles strongly suggests that syntax and semantics are different sides of the same coin, and insofar as an underlying semantic basis exists for the syntax of 
adjectives, their semantics can also be better understood through distributional analyses of their syntax.

A macroscopic analysis of the category reveals that around $80 \%$ of the distribution of adjectives can be accounted for by examining two primary syntactic functions, i.e. within noun phrases and following copula verbs, herein described as "adnominal" and "predicative". Of the two, adnominal occurrences are about four times as common (approximately $63 \%$ vs. $16 \%$ ), but particular adjectives or adjective micro-classes may show a strong predisposition toward one function or the other. Three of the semantic families included in this study, adjectives of age (old, young), size (large, small, big) and color (black, white, red etc.), are predominantly adnominal, in keeping with the overall tendency, while two others, adjectives describing modal concepts (possible, impossible, likely) and those that convey emotions or attitudes (happy, sad, glad, sorry) are moderately or strongly predisposed to predicative function. Depending on their predisposition, further syntactic patterns may be described with respect to each primary syntactic function: for adnominally predisposed adjectives an affinity with certain determiners (or lack thereof) and for predicatively predisposed adjectives an affinity with certain types of subjects. Adjectives denoting age are strongly associated with the definite article, adjectives of size (with the exception of big) co-occur most frequently with the indefinite article, while all most frequent determiners are found in similar proportions with adjectives of color. Within each family of predominantly predicative adjectives, some - possible, impossible and necessary among modal adjectives, happy and sad among adjectives of emotion - are used principally or exclusively with third-person subjects, while others, such as sure, glad and sorry, are used more often with first-person subjects. Syntactic distributional analysis thus also reveals that underneath an obvious "family resemblance" individual adjectives also have their own distinctive profile.

Intensifiers, the other main constituent of the adjective phrase, are found much more frequently in predicative occurrences (with the notable exception of sure). Most gradable adjectives, moreover, are not simply susceptible to variation in degree, but display an affinity with, or, conversely, a resistance to specific forms of intensification. Adjectives of age, for example, are commonly used in the comparative form, but most other forms of intensification occur less frequently than the overall average for the category. Paradoxically, likely, glad and sorry are more receptive to intensification than adjectives in general and yet are seldom found with comparative or superlative marks, the most common forms of intensification. Similarly, big is highly receptive to intensification, especially in predicative function, and yet seems resistant to very, which is often considered one of the most prototypical adjectival modifiers (Quirk \& Greenbaum [1985: 403], Huddleston \& Pullum [2002: 528], inter alia).

In some cases, a semantic explanation or corollary is readily apparent: modal adjectives such as possible, impossible and necessary, which in their strictest logical sense quantify events in possible worlds, are typically used with extraposed infinitives or clauses, while likely and sure, which express less easily formalized para-modal concepts such as expectation or confidence, are thus more open to variation in degree and more compatible with personal subjects (and more similar in this respect to adjectives expressing attitudes or emotions). Adjectives describing colors at opposite ends of the spectrum or scale of luminosity are more susceptible to intensification than those that describe colors in the middle zone. Greater potential for enantiosemic or polysemic 
shifts in meaning appears to be one of the factors underlying the greater syntactic versatility of adjectives such as sure, happy and sad.

The present study, however, opens up perspectives for further qualitative analysis and inquiry into the underlying cognitive mechanisms at the semantics-syntax interface which can only be hinted at using quantitative data alone. Two of the most important questions which have come to light are, first of all, how semantic interactions between the determiner, adjective and noun within the noun phrase and the wider context contribute to adjective-determiner associations like those observed between adjectives of size and the indefinite article, or between adjectives denoting age and the definite article, and, secondly, how different forms of intensification modify the interpretation of the adjective.

\section{BIBLIOGRAPHY}

BAKER Mark, 2004, Lexical Categories: Verbs, Nouns and Adjectives, Cambridge: Cambridge University Press.

CRUSE Alan D., 1976, “Three classes of antonym in English”, Lingua, 383-4, 281-292.

DIXON Robert M.W., 2005, $2^{\text {nd }}$ ed., A Semantic Approach to English Grammar, Second Edition, Oxford: Oxford University Press.

DIXON Robert M.W. \& AIKHENVALD Alexandra, 2004, Adjective Classes: A Cross-linguistic Typology, Oxford: Oxford University Press.

FIRTH John Rupert, 1968, “A Synopsis of Linguistic Theory 1930-55”, in PALMER F.R. (Ed.), Selected Papers of J. R. Firth 1952-59, Longmans: London and Harlow, 168-205.

FRAWLEY William, 1992, Linguistic Semantics, New York: Routledge.

HENKEL Daniel, 2014, L'Adjectif en anglais et en français : syntaxe, sémantique et traduction, Thèse de Doctorat, Université Paris Sorbonne.

HUDDLESTON Rodney \& PULLUM GEOFFREY K., 2002, The Cambridge Grammar of English Language, Cambridge: Cambridge University Press.

KENNEDY Christopher, 2007, "Vagueness and grammar: The semantics of relative and absolute gradable adjectives", Linguistics and philosophy, 301, 1-45.

MUEHLEISEN Victoria, 1997, Antonymy and Semantic Range in English, Ph.D. dissertation, Evanston, IL, Northwest University.

MURPHY Gregory \& ANDREW Jane, 1993, "The conceptual basis of antonymy and synonymy in adjectives", Journal of memory and language, 323, 301-319.

PARADIS Carita, LÖHNDORF Simone, VAN DE WEIJER Joost \& WILLNERS Caroline, 2015, "Semantic profiles of antonymic adjectives in discourse", Linguistics, 531, 153-191.

QUIRK Randolph, GREENBAUM sidney, LEECH Geoffrey \& SVARTVIK Jan, 1985, A Comprehensive Grammar of the English Language, London and New York: Longman. 


\section{Corpora}

ANTHONY Laurence, 2018. AntConc Version 3.5.8 [Computer Software]. Tokyo, Japan: Waseda University. Available from https://www.laurenceanthony.net/software

HÜNING Matthias, TextSTAT 2.9c [Computer Software], Freie Universität Berlin, http:// neon.niederlandistik.fu-berlin.de/en/textstat/

sCHMID Helmut, TreeTagger [Computer Software], Universität Stuttgart, http://www.cis.unimuenchen.de/ schmid/tools/TreeTagger/

\section{NOTES}

1. The author wishes to thank two anonymous reviewers for their helpful comments, and the editors of this volume for their patience and support in the midst of an unprecedented global crisis.

2. Whereas in Henkel [2014] only be was taken into account as the most common copula verb, for this study a full inventory was first conducted of all constructions in which a verb introduced an adjective not followed by a noun. Of the 61,514 occurrences, over $77 \%$ were found to contain be, while six other verbs were found to occur in 1-2\% of such constructions: grow (1.8\%), seem (1.7\%), become (1.6\%), look (1.4\%), get (1.3\%) and feel (1.3\%). All other verbs were present in fewer than $1 \%$ of the examples, many of which such as "breathe hard" or "sleep late" would be better analyzed as adverbial uses of ambivalent forms rather than predicative constructions involving adjectives. Others, such as "go" form collocations with a relatively small number of adjectives: "go crazy" "go dry". Insofar as they represent close to $90 \%$ of all predicative constructions, the six copula verbs included in the search query thus provide a reasonably good estimation of the predicative potential or predisposition for most adjectives.

3. As is commonly recommended when the population standard deviation is unknown and the number of measurements is inferior to 30 .

4. The adverbs taken as indicators of receptivity to intensification in this study are not, of course, the only intensifiers that can be used in adjective phrases, but were found to be the most frequent and together comprise around $50 \%$ of all adverb+adjective constructions. One other potential intensifier, as, was found to occur with a frequency similar to that of too, but was excluded due to its greater ambiguity, as evidenced in the following examples: And as he touched her - it was a hot hand he touched - it struck him as absurd to be quibbling about why she had gone. (S. Glaspell, The Visioning) And meanwhile, his flat was dark, as well as stuffy. (E.M. Forster, Howards End)

5. This pattern is consistent with that reported in Henkel [2014: 282] despite the somewhat lower percentages, the discrepancy being due primarily to a difference in the method of calculation: percentage of total number of tokens vs. percentage of adnominal occurrences only.

6. These percentages were obtained from the present corpus using regular expressions and thus differ slightly from those reported in Henkel [2014] based on manual analysis of smaller corpora, but nonetheless confirm the same general tendency observed previously.

7. It is worth noting that a somewhat similar distinction is made by Muehleisen [1997: 168] between sad and unhappy on the basis of event-related meanings ( $s a d$ ) vs. situation-related meanings (unhappy). 


\section{ABSTRACTS}

Twenty adjectives belonging to five intuitively recognizable semantic families, age (old, young), size (large, small, big), color (black, white, red, yellow, blue), modality (possible, impossible, necessary, likely, sure) and emotion (happy, sad, glad, sorry) were inventoried in a 5-million word corpus tagged for part of speech (POS) and lemma. Regular expressions were used to target specific contextual parameters including syntactic function (adnominal or predicative), determiners, grammatical subject and intensifiers, while manual estimates were obtained from random samples of 500 occurrences per adjective. Benchmark data, for purposes of comparison, were first collected for the category as a whole using POS tags, from which it was observed that four major determiners and six copula verbs were present in $80-90 \%$ of all occurrences. Adjective families were found to share common, distinctive syntactic profiles, with similar predispositions to adnominal or predicative function and similar affinities with specific determiners or intensifiers. Differences were observed as well between certain quasi-synonyms such as glad/ happy with respect to one or more of these criteria.

Vingt adjectifs appartenant, d'un point de vue sémantique et intuitif, à cinq familles, à savoir ceux qui décrivent l'âge (old, young), la taille (large, small, big), la couleur (black, white, red, yellow, blue), la modalité (possible, impossible, necessary, likely, sure) et les émotions (happy, sad, glad, sorry), ont été inventoriés dans un corpus de 5 millions de mots étiquetés par catégorie grammaticale et lemme. Des formules de recherche par expressions régulières (regex) ont été conçues pour viser certains paramètres contextuels, notamment la fonction syntaxique (adominale ou prédicative), le déterminant, le sujet grammatical et les marques d'intensification, tandis que, par ailleurs, des estimations manuelles ont été obtenues à partir d'échantillons aléatoires de 500 occurrences pour chaque adjectif. À des fins de comparaison, des données de référence ont été récoltées pour la catégorie dans son ensemble à partir des étiquettes grammaticales, ce qui a permis d'observer que quatre déterminants principaux et six verbes copules sont impliqués dans $80-90 \%$ des occurrences. Au sein de chaque famille d'adjectifs, l'on retrouve un profil syntaxique distinctif commun quant à leur prédisposition à la fonction adnominale ou prédicative et leurs affinités avec certains déterminants ou marques d'intensification. L'examen de ces critères syntaxiques fait aussi ressortir quelques différences entre des quasi-synonymes tels que glad/happy.

\section{INDEX}

Mots-clés: adjectifs, linguistique de corpus, fonction syntaxique, déterminants, sujet grammatical

Keywords: adjectives, corpus linguistics, syntactic function, determiners, grammatical subject

\section{AUTHOR}

\section{DANIEL HENKEL}

Université Paris 8 Vincennes - Saint-Denis

daniel.henkel@univ-paris8.fr 